\title{
NET-1.2 Post-Irradiation Examination Report
}

Michael Rightley, Matt Ales, Susan Bourcier

Prepared by

Sandia National Laboratories

Albuquerque, New Mexico 87185 and Livermore, California 94550

This work was supported by the Air Force Phillips Laboratory under Contract 64920110 .

Approved for public release; distribution is unlimited.

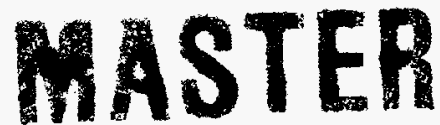

\section{Iii Sandia National Laboratories}

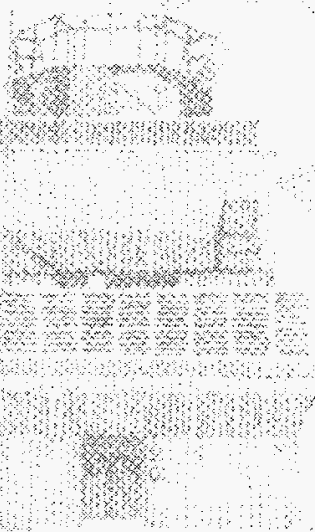

$S F 29000(8-81)$

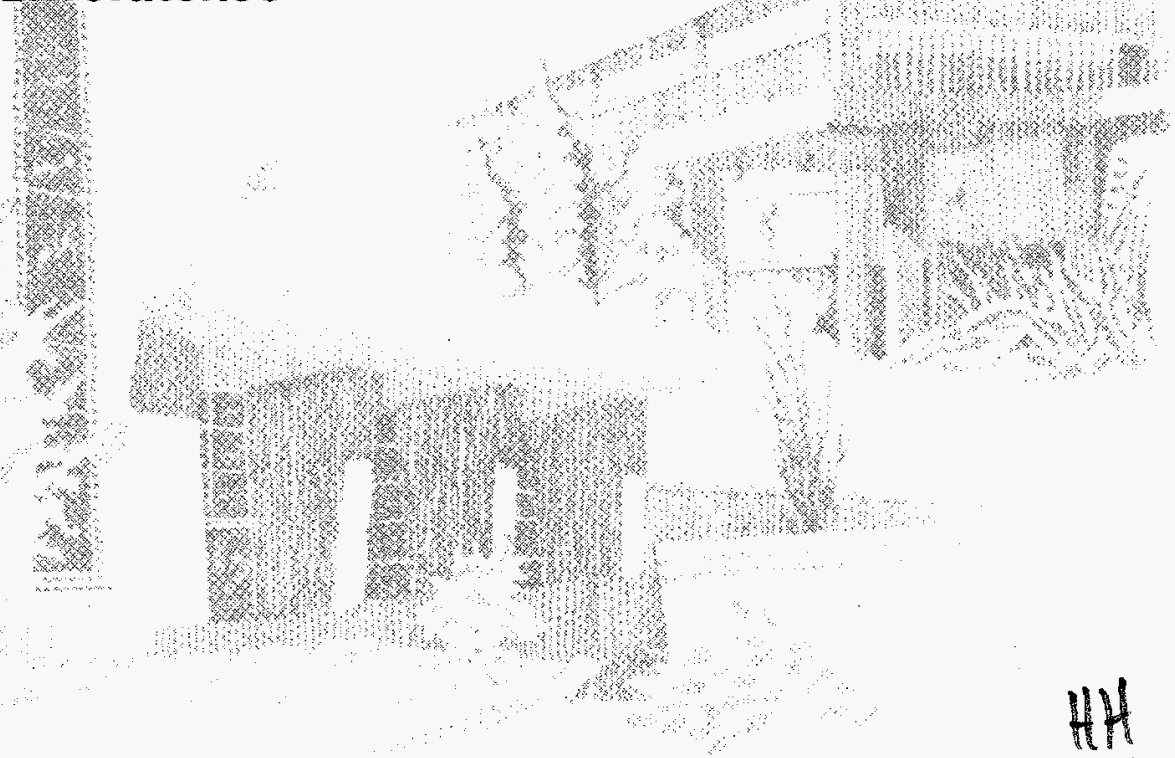


Issued by Sandia National Laboratories, operated for the United States Department of Energy by Sandia Corporation.

NOTICE: This report was prepared as an account of work sponsored by an agency of the United States Government. Neither the United States Government nor any agency thereof, nor any of their employees, nor any of their contractors, subcontractors, or their employees, makes any warranty, express or implied, or assumes any legal liability or responsibility for the accuracy, completeness, or usefulness of any information, apparatus, product, or process disclosed, or represents that its use would not infringe privately owned rights. Reference herein to any specific commercial product, process, or service by trade name, trademark, manufacturer, or otherwise, does not necessarily constitute or imply its endorsement, recommendation, or favoring by the United States Government, any agency thereof, or any of their contractors or subcontractors. The views and opinions expressed herein do not necessarily state or reflect those of the United States Government, any agency thereof, or any of their contractors.

Printed in the United States of America. This report has been reproduced directly from the best available copy.

Available to $\mathrm{DOE}$ and $\mathrm{DOE}$ contractors from

Office of Scientific and Technical Information

P.O. Box 62

Oak Ridge, TN 37831

Prices available from (615) 576-8401, FTS 626-8401

Available to the public from

National Technical Information Service

U.S. Department of Commerce

5285 Port Royal Rd

Springfield, VA 22161

NTIS price codes

Printed copy: A03

Microfiche copy: A01 
SAND 94-1261

Unlimited Release

Printed June 1997

\title{
NET-1.2 Post-Irradiation Examination Report
}

\author{
Michael Rightley \\ Reliability Physics, MS-1081 \\ Sandia National Laboratories \\ P.O. Box 5800 \\ Albuquerque, NM 87185 -1081 \\ Matt Ales \\ Babcock \& Wilcox \\ Naval Nuclear Fuel Division \\ Susan Bourcier \\ Nuclear Systems Research, MS-1145. \\ Sandia National Laboratories
}

\begin{abstract}
The post-irradiation examination (PIE) of the NET-1.2 fuel element was completed in December, 1993. The goal of the PIE work was to gather data regarding the fracture of the hot frit during the experiment. Five cracks were observed in the hot frit at various locations although only two were believed to have initiated the overall component failure. These two cracks were complete circumferential failures and were located near the open and closed ends of the frit within the active flow region. The location and orientation of these fractures suggested that failure was the result of thermally-induced stresses that exceeded pre-test predictions. The cause of the failure was the temperature difference between the coolant flowing through the hot frit and the thermally massive end fittings. The resulting axial temperature gradients in the hot frit imposed thermal stresses that exceeded failure in the frit coating material. This coating fracture then propagated through the graphite substrate. Post-test analyses of the frit response based on measured data from the experiment verified that the frit coating failure stresses were exceeded.

Additionally, the cold frit behaved unexpectedly. The PIE inspection of this component showed that a majority of the compliant panels were permanently deformed against the cold frit inner wall even though the transients that the bed was exposed to were not thought to be capable of creating this magnitude of bed expansion. No evidence of bed locking was observed. A calculational error in the prediction of the total bed expansion was found (post-PIE) which certainly contributed to the under-estimation of the bed displacement. Additionally, temperature differences between the bulk of the frit and the panels created a bowing force which may have allowed some amount of bed settling at relatively low temperatures while particle thermal expansion was minimal. These panel deformations then became permanent when larger temperature changes in the capsule created stresses which exceeded yield.
\end{abstract}




\section{DISCLAIMIER}

Portions of this document may be illegible in electronic image products. Images are produced from the best available original document. 


\section{DISCLAIMER}

This report was prepared as an account of work sponsored by an agency of the United States Government. Neither the United States Government nor any agency thereof, nor any of their employees, make any warranty, express or implied, or assumes any legal liability or responsibility for the accuracy, completeness, or usefulness of any information, apparatus, product, or process disclosed, or represents that its use would not infringe privately owned rights. Reference herein to any specific commercial product, process, or service by trade name, trademark, manufacturer, or otherwise does not necessarily constitute or imply its endorsement, recommendation, or favoring by the United States Government or any agency thereof. The views and opinions of authors expressed herein do not necessarily state or reflect those of the United States Government or any agency thereof. 


\section{CONTENTS}

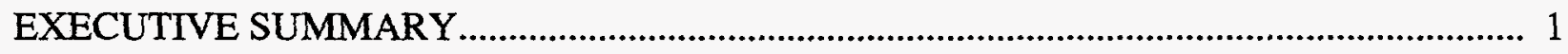

1. INTRODUCTION

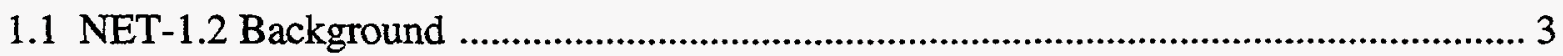

1.2 Objectives and Scope of PIE Work .......................................................................... 4

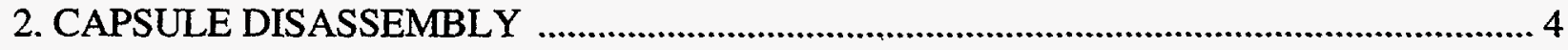

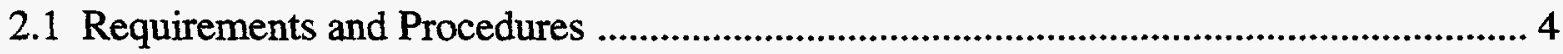

2.2 Disassembly Process...................................................................................................... 5

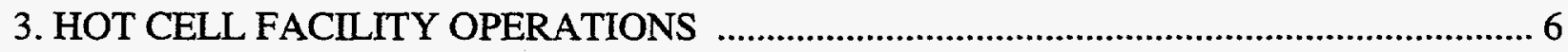

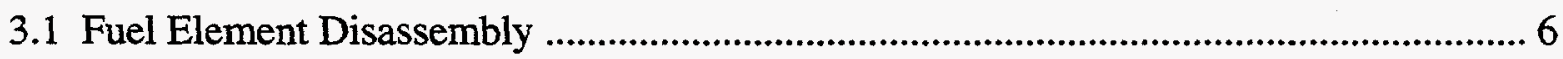

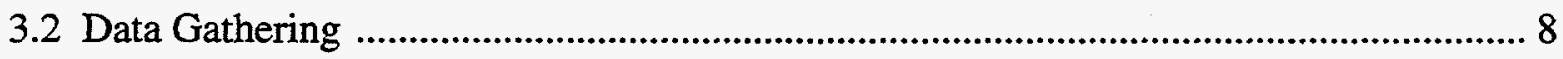

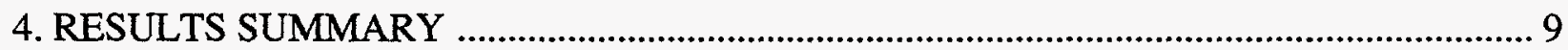

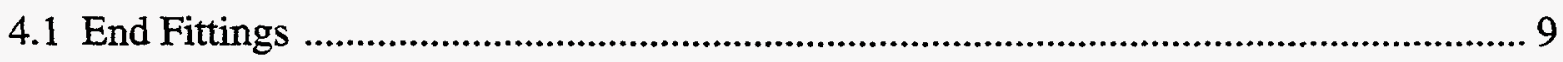

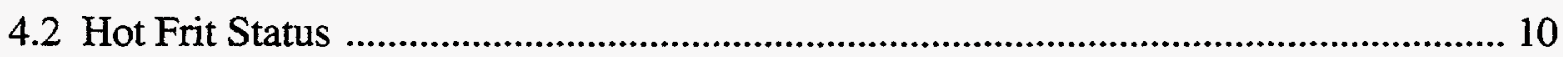

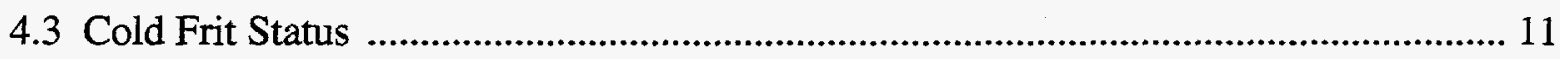

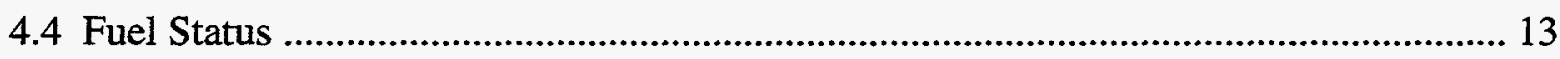

5. COMMENTS ON POSTULATED FAILURE MODES ………......................................... 13

5.1 Complete Circumferential Breaks (Cracks \#1 and \#2) .............................................. 13

5.2 Axial Crack in Center Section of Frit (Crack \#3) ..................................................... 17

5.3 Circumferential Crack at Termination of Center Section Axial Crack (Crack \#4) ...... 17

5.4 Plastic Deformation of the Cold Frit Compliant Layer Panels .................................... 17

5.5 Small Axial Crack in Hot Frit Closed End Stub (Crack \#5) ........................................ 19

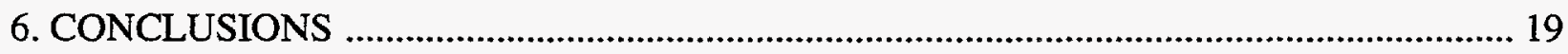

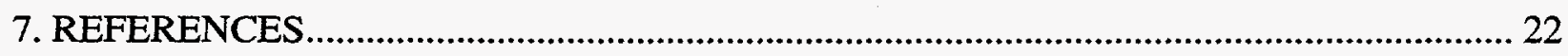




\section{LIST OF FIGURES}

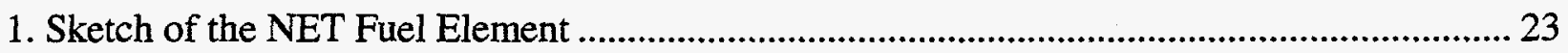

2. Hot Frit Sections in Relative Positions .......................................................................... 24

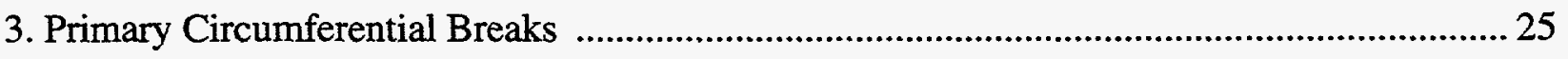

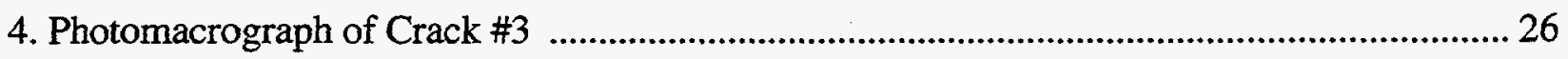

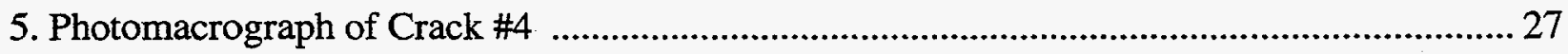

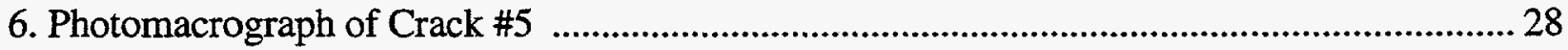

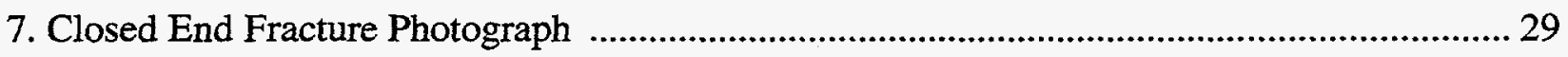

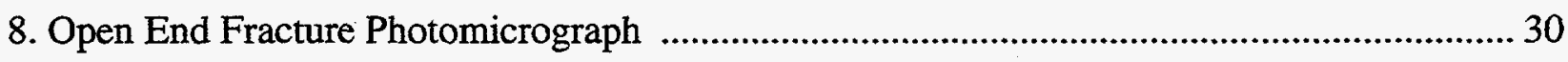

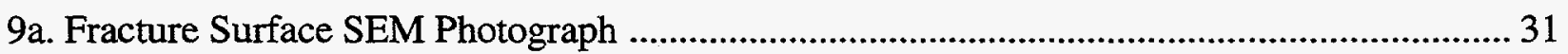

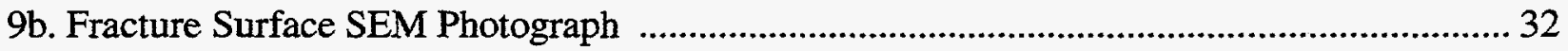

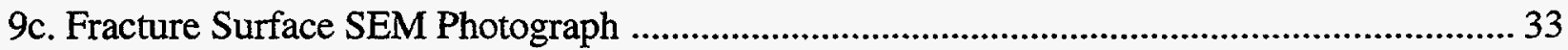

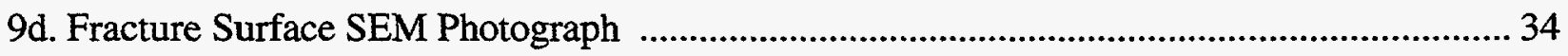

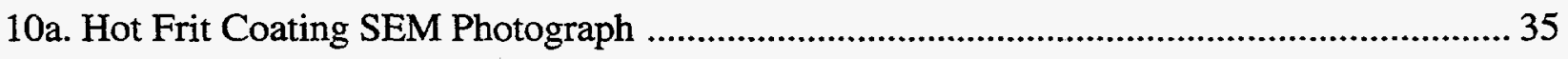

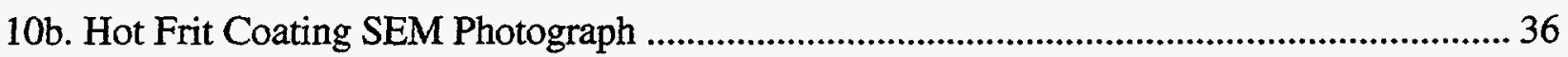

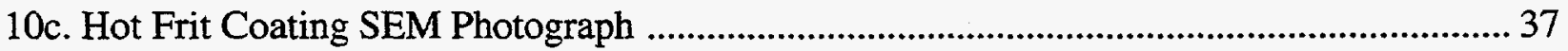

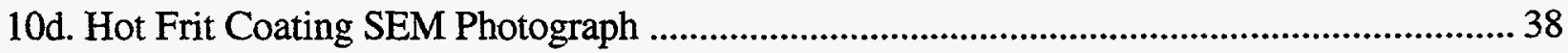

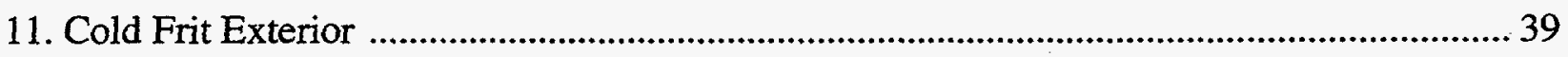

12. Sketch of Observed Compliant Panel and Predicted Bed Locked Configurations ............... 40

13. Optical Macrograph of Representative Whole Particle Fuel ............................................ 41

14. Scanning Electron Micrograph of Representative Whole Particle Fuel ............................. 42

15. Scanning Electron Micrograph of Cross-Sectioned Representative Particle Fuel ............... 43 


\section{EXECUTIVE SUMMARY}

The apparent failure of the hot frit in the NET-1.2 fuel element which was observed in the test series that occurred in June of 1993 in Sandia's Annular Core Research Reactor prompted the Space Nuclear Thermal Propulsion Program (SNTP) sponsor, the USAF Phillips Laboratory, to perform a minimal post irradiation examination (PIE). This PIE effort was intended to gather and evaluate data on the failure of the hot frit. That information could then be used by researchers to generate informed estimations regarding issues that could have bearing on the fuel element or experiment capsule design process (such as timing of the failure, modality of the fractures and reasons for the overstressed situations that led to failure).

The NET-1.2 PIE activities occurred during the months of November and December 1993 in the Hot Cell Facility (HCF) at Sandia. Detailed disassembly procedures were developed to satisfy the safety concerns with the operation (i.e., related to the relocated fuel and the potential for contamination) and to preserve the data from any fractured pieces of the fuel element that may exist. Consequently, the element was carefully removed from the test capsule keeping it in a vertical orientation. As expected, when the seal between the fuel element and the element mounting tube was broken, several grams of fuel particles were released and captured in a contamination control bag. These particles were located above the element/mounting tube interface prior to breaking the seal. Additionally, some particles were liberated from the heat sink area afterwards when the outside of the package was gently struck with a rubber mallet.

After being transferred to the $\mathrm{HCF}$, the particles in the central gas flow channel were aspirated out in $20 \mathrm{cc}$ samples and the inner surface of the hot frit was inspected boroscopically. Ultimately, five cracks were found on the hot frit; two complete circumferential fractures (through the thickness), both in the active flow region about $3 / 8$ inch in from each end, one longitudinal fracture (also through thickness) that extended from the closed end circumferential crack about 4 inches upward along the frit wall, one small partial through-wall circumferential fracture which was very close to the termination of the main longitudinal crack, and one fracture that extended beyond the flow region of the lower part of the frit near the closed end.

Initial optical inspections of the failures indicated several important points. First, the presence of fuel particles in the through-thickness axial crack suggested that this failure was caused by unexpectedly large hoop stresses in the frit wall. The most likely explanation is that this occurred after the two circumferential breaks formed, when a significant amount of fuel had relocated into the central channel. This situation would have resulted in an unexpectedly large differential thermal expansion between the fuel and the frit material which occurred during the confirmatory coupling factor (i.e., uncooled) runs at the end of the experiment. Due to the fuel relocation, the frit would then have been exposed to fuel on both sides near the closed end. Large thermallyinduced hoop stresses, created by the anomalous fuel distribution, probably exceeded the allowable levels in the frit during these runs. Post-test analyses simulating the stresses created by 
a relocated fuel bed were consistent with this theory indicating stresses which exceeded failure levels by significant amounts.

Secondly, the apparent uniform appearance and almost symmetrical location of the two major circumferential breaks (i.e., based on distance from the beginning of the flow region of the frit) suggested that these failures were the result of excess thermal stress placed on the hot frit wall. Post-test analyses indicated that the general location of the failures was consistent with regions of peak stresses (i.e., near the hot frit/end fitting interfaces). The exact locations of the stress maxima, as predicted in the thermal/structural analyses, lie at the hot frit/end fitting interfaces which is roughly $3 / 8$ " away from the two breaks. This difference can be attributed to differences between the boundary conditions of the analytical model and the actual transient conditions which existed during the experiments. Additionally, some uncertainty can be attributed to the low spatial resolution of the "hot frit wall" temperature measurements.

The causes of the two small cracks are unknown although both are believed to be artifacts of the initial failures which allowed the fuel relocation. The through-wall crack extending downwards from the lower circumferential fracture to the bottom of the frit was probably caused by differential thermal expansion created when fuel particles became trapped between the stainless-steel thermocouple plug and the hot frit wall. PIE inspections revealed that fuel had relocated from the central channel (after the lower failure had occurred) past the thermocouple plug and was removed from the closed end cap. If any of these particles were lodged between the plug and the frit during a reactor transient, differential thermal expansion between the thermocouple tree plug and the cooler hot frit wall would have been coupled through the particles and failed the hot frit.

The two major circumferential fracture surfaces were examined in a scanning electron microscope. The results of this inspection indicated the failures were primarily intergranular in nature (i.e., along the grain boundaries) and that there were two to three grain diameters present through the $\mathrm{NbC}$ coating thickness. There was also some evidence of defects in the coating away from the vicinity of the fractures, indicating the presence of "as-fabricated" coating defects. This information indicates that there may be an optimal number of grain diameters in the through thickness coating, based on the load partitioning between the coating and the graphite substrate, that provides for a more robust design. Due to the difficulties associated with the process, detailed non-destructive inspections of the frit were not performed. Underestimation of the fraction of the total load that is applied to the coating material and lack of accurate knowledge of the as-fabricated coating morphology probably contributed to the lack of coating performance.

The cold frit was also studied, although much less carefully than the hot frit. It was observed that practically all of the cold frit compliant panels were deformed close to or at their maximum predicted operational deformation. The shape of the panels was roughly parabolic. This shape suggests that the fuel bed was never fully "locked" between the hot and cold frits and therefore reduces the probability that hot frit failure was due to loading from the bed. If complete bed locking had occurred, we would have expected to see a compliant panel shape that was square and left no free volume between the panel and the inner cold frit wall. 
Additionally, fuel particles could be seen lodged between the panels and the grid structure. This situation may have contributed to the inability of the panels to return to their unstressed state. (Recall that, if the deformation stresses are below the yield of the panel material, the panels should return to a relatively flat position after the loads have been removed.

The fuel was sequentially collected and labeled according to the order that it was removed from the element. A metallographic examination of the particles that were removed from the vicinity of the lower circumferential fracture was conducted. The results indicated that the fuel was never thermally threatened during the testing, even to the point that no discoloration was observed. No signs of crushed or fractured fuel could be found, indicating that the failure of the hot frit occurred before any mechanical or thermal stresses on the particles were large enough to approach their yield points.

The problems which led to the failure of the hot frit are not thought to be inherent design limitations or physical limitations on the performance of the materials chosen. Some improvement of the coating process would be required to allow the application of thicker coatings with many grains through the thickness and to eliminate as-fabricated coating defects which may have served to reduce the failure strength of the frit. In addition, accurate design calculations of the thermal expansion of the bed will allow for proper designs to accommodate this phenomenon.

Further, based on the appearance and the resulting postulation regarding the permanent deformations of the compliant panels, we feel that the cantilever panel design approach proposed by $\mathrm{B} \& W$, would significantly improve the performance of the layer. Additionally, improved analysis of the thermal response of the hot frit/end fitting interfaces would allow better prediction of the actual thermal gradients that the hot frit must withstand. This information, along with improved pre-test component inspections, would allow the fabrication of new frits (using the same materials) that could withstand the conditions imposed by the NET-1.2 test matrix.

\section{INTRODUCTION}

\subsection{NET-1.2 Background}

The Nuclear Element Tests (NET) were designed to provide data which would be used to evaluate the performance of particle bed nuclear fuel elements. Out of the intended series of tests that were originally planned, only the first test, NET -1.2 was run. This test was conducted during the month of June 1993 in the Annular Core Research Reactor (ACRR) at Sandia. Shortly before the test was run, the termination of the program was initiated by the sponsor. This situation eventually resulted in the decision to continue with the NET-1.2 experiment since a large fraction of the effort was already completed. However, no contingency was made for any post-irradiation examination (PIE). 
During the performance of the test series, some anomalous data were observed which indicated that fuel had relocated from the annulus volume that it originally occupied into the central gas flow channel and possibly up into the heat sink region. This relocation, which was confirmed through an X-radiograph of the capsule after removal from the ACRR, indicated that the niobium carbide $(\mathrm{NbC})$ coated graphite hot frit had fractured somewhere and that, when the motor/compressor flow system was operated, fuel particles were being blown upwards through the central channel towards the heat sink.

Due to the unexpected status of the fuel element after the test series was terminated, the sponsor decided to fund a minimal PIE of the element to observe the fracture in the hot frit and provide some information on possible scenarios which could have created the failure. The PIE work was initiated in September and the fuel element was removed from the capsule during the second week of November.

\subsection{Objectives and Scope of PIE Work}

Based on the status of the program and the nature of the NET-1.2 test data, the main objective of the PIE was to evaluate the status of the hot frit and gather any other data which may help to determine causes for its failure. If possible, other pertinent data regarding the overall performance of the element and the fuel was gathered, however, this effort was minimal in scope. Some fuel metallography was performed as well as a cursory inspection of the cold frit interior. The main thrust of the effort consisted of a detailed visual and photographic examination of the hot frit and some optical and electron microscopy of the fracture surfaces.

The emphasis of the PIE effort was geared towards maximizing the data gathering and providing the results in a concise form for some future time when nuclear thermal propulsion research activities may be restarted. Consequently, no detailed analysis of the data was performed and this report is only a brief review of the methods and results of the PIE.

This report does, however, include a section on the most plausible postulated failure scenario based on the PIE data and on interpretation of these data by the fuel element manufacturer and metallurgical engineers. This postulated scenario represents the best estimate of the failure of this complex element and is included only for completeness. We caution the reader that the interpretation of the data and the conclusions that were drawn regarding the failure of the element are based on no detailed analysis of the data, which normally would have been performed to address some of the issues that arose had the resources been made available.

\section{CAPSULE DISASSEMBLY}

\subsection{Requirements and Procedures}

To properly remove the fuel element from the NET-1 experiment capsule, two important points were carefully considered. First, the safety of the workers and protection of the facility would have to be ensured. The approval for this type of activity is obtained through the Sandia Reactor 
Criticality and Safeguards Committee (RCSC). Secondly, the element must be handled in such a way as to minimize the destruction of data during the disassembly, removal and transportation to the hot cell facility. To ensure protection of the data, a set of requirements for handling of the fuel element during its removal from the capsule and transportation were negotiated between Sandia and the fuel element manufacturer, Babcock \& Wilcox (B\&W). A document was generated by $\mathrm{B} \& \mathrm{~W}$ as a result of these negotiations ${ }^{1}$ which described the handling and storage methods necessary to maximize data protection.

Additionally, an experiment plan $^{2}$ was generated by Sandia to present to the RCSC for safety approval of the entire PIE process. The plan included, as an appendix, a detailed set of disassembly procedures which were developed in conjunction with $B \& W$ to ensure safe removal of the element while still protecting the integrity of the data.

\subsection{Disassembly Process}

To maintain the vertical orientation of the element throughout the fuel removal and initial interior inspections in the hot cell, the disassembly and removal process occurred in the ACRR high bay (the overall length of the test capsule was too great to allow vertical removal through the high bay roll-up door). A contamination control tent, which had been previously procured for this purpose, was constructed next to the reactor above the dense-pack storage hole into which the capsule had been placed after the experiment.

Immediately after the experiment, the hydrogen was vented from the capsule with approval of the ACRR safety committee. Samples of this gas were collected and measurements were performed on them to detect the presence of fission product gases, prior to venting, to ensure that it was not contaminated. The hydrogen was found to be "clean" indicating that no significant fuel failure had occurred (i.e., failure of individual fuel particles allows release of the fission product gases that are generated during irradiation). The capsule was then backfilled with nitrogen for storage. Also, several radiographs of the fuel element region of the capsule were taken in July to confirm that fuel relocation had occurred and to determine the height of fuel in the central channel. These exposures indicated that fuel filled the central channel to a height that was above the interface location between the open-end flange and the fuel mounting tube to which it was attached. This situation meant that fuel would escape when the seal between the mounting tube and the open-end flange was broken. Figure 1 illustrates the before and after configuration of the element.

After the nitrogen had been vented and the secondary and primary containment vessels had been removed, a system of contamination control bags were placed around the package to contain the fuel spill. Additionally, a container had been designed and constructed to hold the element in place during the removal process. As expected, when the seal was broken and the upper section of package was raised slightly, several grams of fuel particles immediately flowed out into the control bags that had been attached to both the element and the upper section of the package. Also, once the flow had ceased, rubber mallets were used to strike the outside of the package in the heat sink region to dislodge any particles that may have been blown through the lower heat sink plate and 
been captured in that region. This caused more fuel, on the order of $2-5$ grams, to fall into the capture bags.

(This raised the question of how much fuel remained in the heat sink region after the transportation of the element to the hot cell. After all of the fuel had been removed from the element and the capture bags and weighed, it was determined that several grams of fuel were probably still captured in the heat sink region and possibly as high as the compressor plenum. The difficulty associated with additional capsule disassembly to recover the fuel combined with the results of the metallographic work on the recovered fuel indicated no need to attempt to remove the remaining fuel at the present time. This task will be accomplished during the decontamination and decomissioning phase of the program.)

The element was placed into its transport container and this assembly was placed into a heavy leadlined vessel for transport to the hot cell. A fork-lift was used to remove the lead vessel from the transport truck and place it on the ground in front of a large fume hood in the hot cell. This process was directed by both Sandia and B\&W personnel to ensure that no mechanical vibration, shock or static loading was placed on the element.

\section{HOT CELL FACILITY OPERATIONS}

The following section provides a brief description of the steps taken in the hot cell to prepare the element for the PIE. It is provided for completeness and to allow review by later readers to ascertain if the procedures in any way affected the type or quality of the data that were obtained.

\subsection{Fuel Element Disassembly}

Initially, efforts were made to remove as much of the fuel as possible from the element and the surrounding capture bags prior to removal of the element from the transport vessel. Using a vacuum aspiration tube with a $20 \mathrm{~cm}^{3}$ filter installed to capture all particulate matter that is drawn through the tube, the fuel particles were removed from the central channel. To observe and record the process, a lighted boroscope was mounted next to the aspiration tube and the image was recorded on a standard video tape. Additionally, a video camera was used to film the workers and record spoken comments that were made as the work progressed.

As the aspiration process lowered the level of fuel in the central channel, we were able to visually inspect the hot frit inner wall for failure and eventually observed three of the five cracks that were ultimately discovered. Also, near the closed end of the frit, small pieces of the hot frit were observed. These pieces were removed using an aspiration tube that was smaller than the diameter of the piece so that a suction was formed which held the piece in place as it was lifted out. We assumed that the physical characteristics of the pieces were not significantly altered by the removal process since great care was taken to avoid any other contact of the pieces. 
Once all of the fuel was removed from the central channel and the surrounding capture bags, the open end flange was gently tapped while the aspiration tube was inserted to the bottom of the element interior. The tapping caused the fuel which remained in the annulus to release and flow into the central channel for removal. Since the $20 \mathrm{~cm}^{3}$ sample bottles were sequentially numbered and used in the order in which the fuel was removed, the fuel that stayed in the annulus was removed last, even though it probably was initially located near the open end of the element.

After as much of the fuel was removed as possible using the aspiration tube method and since we observed two complete circumferential cracks in the hot frit, the primary method of element disassembly (based on the $B \& W$ requirements document ${ }^{1}$ ) was used to dissemble the open and closed end subassemblies. This step was performed carefully since we recognized that some fuel almost certainly remained in the annulus in the space below the level of the lower circumferential crack.

Among the five cracks in the hot frit were two circumferential cracks, one near the open end and one near the closed end. Because these cracks were complete through-wall failures, three separate pieces of the hot frit were available for removal, simplifying the process considerably. The three pieces were named open end, closed end and center. This allowed the open end assembly to be disconnected from the cold frit without complete disassembly.

After cold frit was disconnected from the open end assembly, the center piece of the hot frit was removed exposing the fuel remaining in the annulus below the level of the lower circumferential crack. The aspiration tube was then used to remove this fuel and the boroscope was inserted to videotape the annulus and the fracture surface on the closed end hot frit piece (it was necessary to use the boroscope since the cold frit was still connected to the closed end assembly).

At that time the fuel element consisted of three pieces; the open end assembly which included the open end piece of the hot frit, the center hot frit piece and the cold frit/closed end assembly which included the closed end piece of the hot frit. Two of these pieces, the open end assembly and the cold frit/closed end assembly, were taken to the ACRR for a neutron radiograph exposure at the request of the $\mathrm{B} \& \mathrm{~W}$ representative. It was hoped that the exposure would allow determination of the presence of fuel particles in the void volumes in the open and closed end assemblies. Additionally, some information concerning the presence of fuel in the cold frit as well as more detail on the state of the compliant panels was expected to be gathered.

After the pieces were radiographed, the open end assembly was carefully disassembled after a boroscope examination of the shield ring gaps verified that they were fully closed (indicating that no fuel had relocated through these pieces). Fuel searches were performed after each component was removed although no fuel was found and nothing unexpected was observed in the open end components.

The closed end assembly was disassembled next. Again, no signs of fuel were found in the void volumes in this assembly with the exception of several particles which were recovered from the 
closed end cap. Additionally, a close boroscope and video examination of the interior of the element near the closed end did not reveal evidence of mechanical interference between the thermocouple assembly and the hot frit.

The components of the fuel element were weighed, either separately or together in some cases to facilitate handling and disposal. These data were presented to the element manufacturer and can be obtained, if desired, from them.

\subsection{Data Gathering}

A brief section outlining the types of activities that were performed to gather the data is included. The order presented roughly corresponds to the order that the tasks were performed.

As discussed above, during the fuel removal and element disassembly operations, videotaped boroscope examinations, standard video photography and a neutron radiograph exposure were made of the element. Data gathered from these examinations include the nature and extent of the hot frit failures, the apparent status of all of the element components and some indication of unexpected behavior in the compliant panels of the cold frit.

After the element was completely disassembled, the specific PIE activities commenced. Initial inspections of each part were made visually and photographically (videotaped boroscopic examinations, standard video camera overall and $35 \mathrm{~mm}$ still photographs). The hot and cold frits (4 pieces) were moved from the fume hood and installed into a glove box for easier handling and to gain access to PIE equipment. These pieces were inspected using an optical photomacrograph which can provide magnifications up to $32 \mathrm{X}$ and provides Polaroid photographs of the specimen.

Photomacrographs of the wide longitudinal crack in the hot frit were made as well as perpendicular exposures of the two circumferential cracks. Eventually, montages of the circumferential fracture surfaces (of the open end and closed end pieces) were made with the photomacrograph system. These montages were used to evaluate areas of the fracture surface that were to be examined at much greater magnification in the scanning electron microscope (SEM).

Initial views of the fractures in the SEM were made prior to the sectioning of the frit pieces. Ultimately, interesting areas of the two fracture surfaces were examined in the SEM. (The decision regarding which areas of the fracture surfaces to examine was made based on probable areas of failure initiation or termination.) Finally, some SEM examinations of regions of the frit at distances far removed from the failures were performed to evaluate the status of the $\mathrm{NbC}$ coating. This allowed comparisons of the coating appearance between areas near the failed region and the "as delivered" status.

Ultimately, four montages of the two circumferential cracks in the hot frit were made. The two that were taken in the optical photomacrograph were taken at $6.3 \mathrm{X}$. Similar montages were made in the SEM at $30 X$. 
Fuel data gathered consisted of standard metallographic examinations. A sample of fuel (approximately $0.1 \mathrm{~g}$ ) was collected and prepared. The fuel was examined photomacrographically at $6.3 \mathrm{X}$ for evidence of discoloration due to chemical attack or coating spallation due to thermal stresses. Additionally, the same fuel sample was examined in the SEM at slightly greater magnifications for the same purpose.

After these inspections were made, the fuel particles (which were collected in a one particle thick layer) were potted, ground to mid-plane and polished to expose the interiors of the particles. These examinations, intended to evaluate the status of the uranium kernel and the surrounding carbon and zirconium carbide coatings, were made in the SEM.

Several inspections of the cold frit were made although measurements of the state of the compliant panels was deemed beyond the scope of the PIE effort. Qualitative information regarding the cold frit was gathered, including data on the presence of fuel particles between the panels and the inner platelet layer of the frit wall. Both the neutron radiograph and various photographic methods provided these data.

\section{RESULTS SUMMARY}

A brief summary of the observed status of the three major element components, including the fuel, is provided. The resulting interpretations of these data are presented in Section 5. Some of the photographs that were taken are included to provide the reader with some of the visual data that were gathered. However, to support the interpretations, all of the data were evaluated.

Inspections of the outside of the fuel element showed no anomalies (i.e., discolorations or mechanical deformations) that would indicate excessive thermal or mechanical stresses or loads.

\subsection{End Fittings}

As stated previously, inspections of the open and closed end assemblies also revealed no anomalies and no fuel particles were found in the end fitting regions associated with the insulators and washer segments surrounding the hot frit (i.e., within the gaps between the individual segments or between the outside diameter of the corrugated springs and the inside diameter of the end fitting retainers ${ }^{3}$ ). This finding appeared to confirm what was observed in the neutron radiograph of these assemblies although the data from the radiograph must not be considered conclusive since the various stainless-steel and hafnium carbide (HfC) components in those regions could have obscured the fuel particles. (One of the postulated scenarios for the hot frit failure was that fuel had relocated into these void volumes and produced undesirable mechanical stresses on the ends of the frit. The inspections of these areas provided no evidence that this occurred.)

The radiograph did indicate that the radial gap between the outside diameter of the washer 
segments and the shield ring segments and the inside diameter of the closed end retainer did not appear spatially uniform from side to side. However, with the fuel bed removed, there was no mechanism in place to maintain the closed end of the hot frit and its related insulators concentric to the cold frit so the non-uniformity of the gap is not considered significant.

All of the insulator segments, washer segments and the HfC shield ring segments appear to be in pristine condition. However, several observations were made concerning the ability to disassemble the end fittings. First, it was quite difficult to remove the wave spring and spacer from the closed end retainer. A notch in the lip of the retainer would have improved this. Second, the subassembly consisting of the washer segments, closed end shield ring segments and the closed end corrugated spring could not be removed intact from within the closed end retainer. The corrugated spring at the closed end of the fuel element was slightly damaged during the disassembly process. Third, the closed end retainer could not be removed form the cold frit with the washer segment subassembly within the retainer.

\subsection{Hot Frit Status}

As described earlier, during the removal of the fuel and the more detailed examination that occurred after the end assemblies were removed, five failures were observed in the hot frit. Two of these cracks were full circumferential breaks that were located approximately $3 / 8$ inch into the fuel bed region from the interface between the fuel and the end fittings. These two breaks divided the frit into three sections, the closed end, center and open end segments. A photograph displaying the three sections in their relative positions is provided in Figure 2.

The breaks were numbered according to the order in which they were observed. Crack \#1 is the open end full circumferential failure while $\# 2$ is the closed end circumferential break. Photographs of these primary circumferential failures are included in Figure 3.

The center section contained an axial (or longitudinal) crack (called \#3) which extended upwards for about four inches from the closed end break. Crack \#3 extended completely through the wall of the frit and a number of fuel particles were observed lodged in the crack. This crack propagated straight along an axial row of pre-existing flow holes and was seen to be widest at the lower circumferential fracture and tapered off as it extended upwards to the central portion of the frit. This indicates that crack \#3 initiated at the lower circumferential break suggesting that it was a secondary failure (i.e., it occurred after the formation of the lower circumferential fracture). Figure 4 is a photograph of this crack taken by the optical photomacrograph camera.

At the termination point of the longitudinal crack (\#3), a small, partial circumferential crack (\#4) which extended only about $30^{\circ}$ azimuthally (approximately $15^{\circ}$ on either side of the intersection with the longitudinal failure) was observed. This crack could not be observed from an interior inspection of the frit wall indicating that it only extended part way through the frit wall. The width of the break was considerably narrower then what was observed for the first three cracks, crack \#3 in particular, although it was readily visible to the unaided eye. Figure 5 presents a photograph of 
crack \#4.

Finally, crack \#5 was detected on the closed end segment of the hot frit. This crack extended the full length of the frit piece and displayed a width similar to crack \#4, much narrower than the three through wall, large breaks. In the section of the piece where the flow holes are located, crack \#5 lies along an axial row of these flow holes in a manner similar to crack \#3, although \#5 is not aligned with \#3. In the solid end region of the frit, the section that extended downward into the closed end fitting assembly, crack \#5 winds around the circumference of the frit for about $30^{\circ}$ (see Figure 6). This crack was observed to penetrate through the frit wall. It was believed that the fuel particles found in the closed end cap may have played a role in the formation of this failure.

No corresponding axial crack through the solid region of the open end frit piece was observed.

The total mass of the three hot frit segments was $0.1 \mathrm{~g}$ greater than the initial mass of the frit even though some small fragments were lost from the closed end circumferential break. This difference can be attributed to the fuel particles lodged inside crack \#3 and to the accuracy of the weighing process.

The circumferential fracture surfaces (cracks \#1 and \#2) of the closed and open ends were examined in the optical macroscope and photographically recorded (Figures 7 and 8 ). The fracture surfaces of both ends were similar. These examinations revealed fairly flat fractures that occurred on a plane which intersected the flow holes. In other words, fracture occurred on the plane of minimal area and of highest stress. There was no through thickness angle to the overall fracture, which implies that there was limited or no plasticity to the overall failure (i.e., a characteristic of brittle failure).

The fracture surfaces were also examined in the scanning electron microscope as shown in Figures 9 and 10. There were three primary findings in examining the fracture surface. First, the fracture surface of the $\mathrm{NbC}$ coating was of a mixed mode, but failure occurred primarily intergranularly (i.e., along the grain boundaries) as shown in Figure 9. Second, faceted porosity defects existed on the grain boundaries as shown in Figure 10. Third, there were approximately 2 to 3 grain diameters which existed through the thickness of the coating as shown in Figure 9.

\subsection{Cold Frit Status}

An inspection of the cold frit exterior revealed nothing anomalous, again indicating no overheating problems or unexpected mechanical loads. A photograph of the cold frit exterior is presented in Figure 11 (the wires visible in the photograph are the lead wires for the internally mounted thermocouples). The amber to bluish color of the frit existed before the test and is the result of the heat treatment process used by the cold frit manufacturer in the construction of the component.

The compliant panels on the inside diameter of the frit are nearly all in a deflected configuration, including those that were above the level of fuel in the bed that existed after the test was completed 
and most of the fuel had relocated into the central channel. It appears, from visual inspection as well as the neutron radiograph, that the panels are touching or nearly touching the inside surface of the cold frit inner wall.

However, the shape of the panels in their permanently deflected state is roughly parabolic in nature. Consequently, there remains free volume between the panels and the inner cold frit wall near the grids into which additional deformation could have, but didn't, occur. This is important in the discussion of the hot frit failure in that it dispels one failure scenario that many considered a significant technical impediment.

If the bed had expanded (by either greater than expected expansion or through ratcheting) to the point where the bed was essentially solid (i.e., "locked"), then the resulting stresses on both frits would be sufficient to fail the hot frit in a hoop compressive mode.

There are two pieces of circumstantial evidence which we feel indicate that bed locking did not occur. First, we believe that the shape of the compliant panels in a bed locked configuration would exhibit "square wave" behavior. We would expect that, in at least some regions of the cold frit inner surface, bed locking would create particle bridges which would tend to deform the compliant panels into shapes which do not indicate nominal bed expansion. There are no such areas on the inner surface of the cold frit - every panel was inspected and found to be deformed parabolically.

The second piece of evidence is the fact that the hot frit failed along two complete circumferential cracks which are both roughly the same distance from the bed/end fitting interface. Horizontal failures indicate axial stresses rather than hoop compression. Also, the number and basic symmetry of the failure locations indicate a probable geometric relationship with respect to the end fitting interfaces. The failure of the of the hot frit in a bed locked configuration would probably occur at only one axial location and would be a hoop compression failure. Hence we conclude that no bed locking occurred in the NET-1.2 fuel element.

All of the deformed compliant panels had fuel particles wedged between their axial edges and the adjacent axial flow separation grid structures. Those panels that do not appear to be as severely deformed do not have these lodged fuel particles.

Additionally, the neutron radiograph picture illustrated at least two locations in which literally hundreds (or more) of particles appear to be captured somehow in the cold frit wall. These pockets of particles lie above the sixth and seventh grids (counted from the beginning of the of the active flow region at the closed end) and appear to be one circumferential grid away from the two panel regions in which one set of wall mounted instruments are installed (i.e., a bellows thermocouple and a panel displacement gauge). The reason for the large numbers of captured particles in these locations is not known, although we assume that the cause is closely related to the capturing of much smaller numbers of particles along the edge of the deformed compliant panels. 


\subsection{Fuel Status}

A minimal investigation of the state of the fuel particles produced no evidence of anomalies. One of the $20 \mathrm{~cm}^{3}$ samples was arbitrarily chosen to provide a representative sample of fuel for the metallographic examination. The results indicated that the fuel was not thermally challenged at the relatively low temperatures that it experienced during the runs that occurred.

Figure 13 shows an optical macrograph of the unsectioned fuel particles. Variations in the apparent color of the particles indicates coating oxidation although it appears slight since no all black or all white particles can be seen (dark particles indicate slight to moderate oxidation). SEM inspection of these particles revealed no evidence of coating spallation (Figure 14), which has been linked in previous studies of these fuel particles to significant oxidation levels. This confirms the conclusion reached about the moderate thermal environment experienced by the fuels.

Figure 15 provides a view of the particle interior taken in the SEM after the particles were ground and polished. The Figure shows no evidence of kernel melt. This information, along with the relatively low level of particle coating oxidation observed, indicates that the particles were not thermally challenged during the experiment, which is consistent with the predicted particle behavior for the low power densities commanded from the ACRR for the runs that were completed.

\section{COMMENTS ON POSTULATED FAILURE MODES}

This section is included to provide the reader with our interpretation of data in terms of the nature and modes of the failures observed in the hot frit and to discuss the results of the post-test analysis that was performed at $B \& W$. Again, we remind the reader that our PIE effort was minimal in nature due to funding constraints. Consequently, in-depth analysis of the data in addition to more detailed data gathering were not performed in this case. Our subsequent attempt to interpret the data based on the limited amount of data and post-test data analysis that was performed must be conservatively considered a best estimate.

\subsection{Complete Circumferential Breaks (Cracks \#1 and \#2)}

The presence of relatively clean circumferential cracks at each end of the hot frit is indicative of failure due to excess thermal stresses. To arrive at this conclusion, we developed a list of plausible failure modes regardless of any estimated probabilities. The list of candidate failure modes is:

1. interference with thermocouple tree mount plug,

2. fuel bed ratcheting (bed locking),

3. relocation of fuel around corrugated spring(s) in the end fittings,

4. binding of the hot frit within the closed end fitting and 
5. excessive thermal stresses at the bed/end fitting interfaces.

Each of the items listed above was considered separately and descriptions of the signatures of these failures were developed. The test and PIE data were the reviewed with respect to the predicted failure signatures and only the excessive thermal stress failure mode appeared consistent with the data.

Of the five items listed, four of them (1-4) would probably have exhibited fractures at only one location due to the localized nature of the high stress regions. Interference with the large stainlesssteel thermocouple tree plug, presumably either from fuel or other debris becoming locked between the frit wall and the plug or from a significant lack of concentricity (or both), would have caused a fracture near the closed end of the frit which would have occurred due to frit/plug mechanical contact over a relatively small contact area. This small area contact would have almost certainly created a much more jagged fracture with significant out-of-plane components around the circumference in contrast to the flat failure surfaces observed (i.e., the failure occurred at the same axial location around the entire circumference). Also, some visual evidence of the contact would have been observed such as marking of the frit wall or coating degradation in the vicinity of the mechanical contact areas. The data do not support this conclusion. Examination of the closed end frit piece and the thermocouple plug did not show evidence of contact. Also, prior to the removal of the closed end frit piece from the assembly, the concentricity was checked as well as particle or debris presence in the gap between the frit and the plug. Neither observation indicated that this contact occurred.

Had bed locking occurred, the expansion volume for the bed would have vanished in the region in which the fuel ratcheting occurred. This situation would have created large compressive hoop stresses on the frit which would also have created a single fracture with considerable out-of-plane components. In addition, the locked bed would certainly have compressed at least some of the panels and eventually formed them into the supporting grid structure against the inner surface of the cold frit prior to the failure of the hot frit (see Figure 13). Although the compliant panels had been permanently deformed, none of them exhibited evidence of bed locking and the appearance of the two "clean" (in-plane) fractures ruled out this scenario as the cause of the failure.

Similarly, had fuel relocated into the void volumes in the closed end fitting assembly, a single failure would have occurred which would also exhibit significant out-of-plane behavior caused by the localized nature of the high stresses. A careful inspection of these volumes was made during the disassembly process for any evidence that fuel had relocated and none was found.

Finally, had the hot frit been axially constrained in the closed end, the resulting failure would also have occurred at one location. Although it is true that the fracture might have occurred cleanly (i.e., in-plane), evidence of the mechanical contact between the end fitting components and the closed end of the frit would have been observed (i.e., regions in which the coating had been degraded or scraped away, frit material debris and scratches on the end cap or other end fittings). Since we found no evidence of this type of contact, we concluded that the data did not support this theory. 
We believe that the evidence obtained in the PIE effort clearly indicates that excessive thermal stresses, caused by larger than expected temperature gradients in the vicinity of the frit/end fitting interfaces at both the open and closed ends of the frit, caused the failure of the component. Some post test analyses were performed to evaluate the response of the frit based on the actual temperature and flow data obtained from the NET experiment records. These analyses, which are briefly described below, support the conclusion.

\subsubsection{Results of Post-Test Analysis}

The analyses performed at $B \& W^{4}$ were intended to simulate the NET experiment transient during which the failure is postulated to have occurred, NET-1.2-9 (a discussion of the test parameters and qualitative interpretation of the data results from the tests are provided in [4]). The frit was modeled using finite element techniques and only the open end area of the frit was included. Since this region would have experienced a relatively lower thermal gradient than the closed end due to the convective heating of the frit in the vicinity of the end fitting and the exhaust, it was assumed that the results would be conservative from the standpoint of failure analysis.

The experiment records were used to dictate the heatup transient experienced during the run using the exhaust gas thermocouple histories. The unperforated section of the frit was heated through conduction from the perforated section, convection with the exhaust gas and radiation. Temperature dependent properties were used to model the thermal and mechanical characteristics of the end fitting materials and convective heating of the end fittings was adjusted during the runs based on the exhaust gas thermocouple readings.

Seven temperature profiles were used, six during the heatup and one for the cooldown. The results of this thermal analysis provided the temperature profiles in the frit material. This information was then applied to a structural model of the frit alone based on the assumption that the end fitting components did not effect the structural response of the frit under heated conditions (axial motion was constrained, however).

The niobium-carbide coating of the frit was modeled as a set of axi-symmetric shell elements applied to the substrate boundary nodes forming the inner and outer surface of the graphite.

The results showed maximum stress levels in the coating elements occurring at the end of the heatup cycle of the transient with peak tensile values of 75 to $90 \mathrm{ksi}$. Since the documented ultimate tensile strength for niobium carbide at room temperature is $35 \mathrm{ksi}$, it is reasonable to assume that the $\mathrm{NbC}$ coating failed sometime during or before the NET-1.2-9 reactor transient. Resulting plots of the axial stresses from the run ${ }^{4}$ show that the peak stresses occur approximately $3 / 8$ to $1 / 2$ inch from the beginning of the perforations, which is consistent with the observed locations of the failures. (Note that only the axial stress component would contribute to the failure of the frit as observed. Plots of Von Mises stress, which are typically presented in finite element structural modeling, showed peak values at the bed/end fitting interfaces. Due to the nature of the fractures, it is appropriate to consider the location of the maximum axial stress in this analysis rather than the 
Von Mises stresses.)

Even though the resulting thermally induced stresses in the graphite substrate were below yield for this run, the situation was re-examined to determine if stress concentrations were created by the cracking of the coating. A second finite element model was created to simulate the tensile testing of the hot frit and the coating structure ${ }^{6}$. The results of this effort showed that a local crack in the coating material increased the stresses in the substrate by an order of magnitude above what is predicted in the thermal/structural analysis. These stress levels would easily have been sufficient to propagate a crack through the wall during the cooldown of the NET-1.2-9 transient, when the graphite stresses were tensile. This conclusion is consistent with the apparent initiation of fuel relocation into the central channel after the conclusion of the -9 transient.

Finally, a repeat of the NET-1.2-9 simulation with a perforated uncoated graphite frit resulted in stresses which were well below the yield strength of unperforated graphite. This may indicate that a monolithic material is a better choice for this component in the NET test environment (although the actual degradation in yield strength due to the perforations should be investigated further).s

\subsubsection{NbC Coating Morphology Results}

A brief discussion of the observed morphology of the $\mathrm{NbC}$ coating on the frit is warranted since the initial failure of the component was likely caused by a thermally-induced stress which exceeded the coating yield limits and eventually was propagated through the substrate via a large magnitude stress concentration created by the localized failed coating. Additionally, it is recognized that significant difficulties exist in attempting to coat substrates when the two materials exhibit differences in mechanical and thermal properties.

The scanning electron microscopic examination of the $\mathrm{NbC}$ coating indicates that the overall failure was brittle in nature and occurred primarily on the grain boundaries (see Figure 9).

The number of grains through the thickness was less than five as observed on the fracture surface. Although the variation of this quantity across the entire surface of the frit is unknown (program funding limitations prevented the development of an appropriate inspection technique), we can assume that the two to three grain thickness is probably a characteristic of the entire component rather than a locally degraded measurement.

Additionally, defects were observed at locations away from the fracture areas which appeared as holes between grains and at multi-grain junctions (Figure 10). These defects increase coating porosity (from the no-defects case) which, when considered together with the small number of through thickness grains, indicates that the overall mechanical integrity of the coating was not optimal for the intended application. (It should be noted however, that the post-test calculations which indicated the higher than expected stress levels in the frit used optimal mechanical properties rather than "as fabricated" values.) Smaller grain sizes and more grains through thickness increases the fracture strength of the material by reducing the probabilities that flaw- 
induced failures will propagate through the coating thickness into the substrate.

The assumption that the grains through thickness value of less than five was roughly uniform across the entire frit surface is based on indications that the initial frit failures were caused solely by the thermal overstressing situation created in test NET-1.2-9. Had local coating degradation been created which either caused the failure or contributed to it, some evidence of this situation would have been noticed and inspections of the coating at other non-failure locations would have indicated significant coating differences from the areas around the fractures. As illustrated in Figure 10, in which the coating was inspected at a location away from the fractures, no evidence of coating differences was found.

\subsection{Axial Crack in Center Section of Frit (Crack \#3)}

The axial crack in the hot frit is most likely a result of having relocated fuel to the hot channel. It is postulated that this crack resulted from the differential thermal expansion between the fuel and the hot frit during the confirmatory coupling factor (uncooled) runs at the end of the experiment. After the lower circumferential failure allowed fuel into the central channel, the hot frit wall in the lower section of the frit would be completely covered, on both sides, with fuel. When reactor transients were run, the heating of this fuel would create large hoop stresses in the frit wall due to the differential thermal expansion between the frit and the fuel. Analyses performed after the PIE data had been gathered indicated that these hoop stresses exceeded failure of the coating and would have caused subsequent fracture of the graphite substrate.

\subsection{Circumferential Crack at Termination of Center Section Axial Crack (Crack \#4)}

Although our uncertainty in the cause of this crack is greater than for the first three fractures, it is probable that this failure and the axial crack (\#3) are related and that they occurred at the same time. One possible explanation is that the axial crack terminated in one of the pre-existing flow holes and that there was sufficient energy remaining to initiate the circumferential crack. Another possible explanation is that the axial crack occurred while there was approximately 4 inches of fuel in the central channel and that the circumferential crack occurred at the free surface of the fuel. In this way, this crack would itself have been created as the result of the differential thermal expansion between the fuel and frit in this region.

\subsection{Plastic Deformation of the Cold Frit Compliant Layer Panels}

We observed that all of the compliant panels showed plastic deformation to a maximum amount of 0.025 " from the unstressed vertical state. This measurement was made by scaling the width of the top of the grid structure and comparing to the maximum depth of the panels and was repeated for several panels in as many locations as feasible. Consequently, the measurement can only be considered accurate to within \pm 0.005 " at best.

Free volumes remained behind each of the panels indicating no bed ratcheting effects. In addition, since the amount of expansion was greater than the design had intended, there was sufficient room 
between the deformed panels and the grid structure to allow fuel particles to become lodged between the panels and the cold frit inner wall. We demonstrated that the set in the panels was permanent by carefully removing the lodged particles behind one of the panels. The panel did not return any observable amount after the last particle was removed indicating that the deformation was plastic and was probably caused by larger than expected bed expansion.

The obvious explanation that the bed got too hot and over-expanded was ruled out since at no time did any of the pertinent instruments indicate such an excursion. (An evaluation of the accuracy and observed functioning of each of the data channels is provided in [4].) Also, the SEM and optical photomacrography of the fuel particles did not reveal oxidation levels consistent with this scenario.

After the visual and photographic inspections of the cold frit compliant panels were completed, the bed expansion prediction models used at $B \& W$ in the design process were reviewed for accuracy prior to performing a complete re-analysis of the expected bed expansion behavior during the actual NET experiment transients using the test data as input. This process resulted in the discovery that a logic error was made in the original expansion prediction model which yielded consistent underestimations of the compliant panel deformations.

The error was found in the loop which aggregates the bed expansion contributions from each of the discreet "nodal volumes" to determine the total. When the test conditions of the NET-1.2-9 transient were used in the corrected model, the results showed a compliant panel deformation of 0.028 " at the maximum temperature measured during the transient which is well beyond the plastic limit of the panels. This value is close to what was measured on the cold frit during the PIE and we concluded from this that the logic error that was made in the pre-test predictions of the bed expansion was the primary contributor to the anomalous compliant panel state.

However, one other possibility must also be considered based on the PIE data as well as the measurements taken during the experiment. This concern was raised based on our review of the data recorded during the tests. We observed that the temperature difference between the compliant panels and the bulk of the cold frit was greater than we had predicted during the pre-test analysis. The localized gradients between the panels and the inner cold frit wall and grid structures would have created a situation in which thermal expansion mismatches could occur. The result is that a bowing force would be placed on the panels as their expansion was driven by higher temperatures than the supporting grid structures. This force would tend to push the panels outward (radially), since inward motion was constrained by the bed.

The situation would be compounded when the fuel particles started to become trapped between the panels and the grids. Had the panels still been elastic when the fuel lodging started to occur, these trapped particles could then prevent the panels from returning and cause them to yield in tension upon cool-down to cryogenic temperatures in preparation for the next transient. This behavior is significantly different from the planned performance of the compliant layer in which the panel deflections follow the thermal expansion and contraction of the bed. Hand calculations 
indicate that a relatively small (on the order of several hundred degrees F) temperature differential between the compliant layer and the bulk of the cold frit could produce panel deflections much larger than those predicted from fuel bed expansion. If this scenario is correct, the cantilever design of the compliant layer would offer much better performance.

Although significant uncertainty exists due to the lack of data and corresponding analyses regarding the anomalous behavior of the cold frit compliant panels, we feel that these two causes, one postulated (bowing-induced motion) and one certain (calculational error), are the most likely explanations.

\subsection{Small Axial Crack in Hot Frit Closed End Stub (Crack \#5)}

This axial crack is in a different azimuthal position from the one in the middle section of the hot frit. This indicates that the two cracks were not related to each other and therefore does not refute the theory put forth above explaining the cause of the larger axial crack (\#3).

We believe that the presence of fuel particles in the closed end cap provides the information that explains this crack. We know that sufficient clearance existed between the stainless steel thermocouple tree plug and the hot frit wall down to the end of the frit to pass fuel particles. This clearance was specifically designed into the thermocouple tree components to prevent thermal stresses in the hot frit due to the differential thermal expansion of the two parts. Once the initial circumferential fracture occurred and particles relocated into the central channel, some particles migrated down into this annular volume and were eventually recovered from the closed end cap during the PIE.

If some of these particles became lodged between the frit and the plug during one of the reactor transients, the differential thermal expansion between the hotter thermocouple tree plug and the cooler hot frit would have coupled through the particles to create stresses on the frit wall that would have certainly exceeded failure. Although no particles were recovered from this lodged position, it is reasonable to assume that this scenario is what caused crack \#5.

\section{CONCLUSIONS}

In all probability, the NbC-coated graphite hot frit used in the fuel element of the NET-1.2 experiment failed due to excessive thermal stresses that exceeded the failure limits of the coating and the graphite substrate. These stresses were unexpected but have been confirmed by re-analysis of the thermal distribution in the frit based on the temperature differences between the flowing hydrogen and the thermally massive end fittings that were measured during the test. In addition, we attribute some contribution to these larger than expected stresses to the understimation of the 
thermal expansion of the bed which occurred through calculational errors in the design process. $\mathrm{s}$

Since pre-test analyses showed closer thermal equilibrium between the coolant and the thermocouple tree structure than was measured, the axial temperature profile which was predicted indicated a gradient less than actually existed. When the post-test analyses were performed using the temperature history of the lowest thermocouple in the tree (i.e., closest to the closed end) and with the material properties of the coating and the substrate considered discreetly (instead of in a bulk fashion), results indicated that the $\mathrm{NbC}$ coating would experience thermal stresses beyond its failure limit and the resulting stress concentration would fail the graphite substrate.

The fracture patterns observed in the two complete circumferential breaks near the top and bottom of the perforated section of the frit are consistent with this type of failure scenario. Additionally, these failures are very close to the locations of the predicted peak principal stresses based on the thermal gradients in the frit. Morphological examinations of the $\mathrm{NbC}$ coating showed two to three grains through the thickness and some faceted porosity defects between grains. Additionally, the fracture areas indicated brittle failure along grain boundaries. The small number of grains through the thickness is undesirable when coating with brittle materials such as NbC. The implication is that the coating process was not optimal for the intended application and significant strength and hydrogen barrier performance improvement may be realized through the optimization of the coating process.

We conclude, from this information, that; 1) the data support the excessive thermal gradients failure scenario, 2) graphite failure was caused by a significant stress concentration in the vicinity of the coating failures (analysis indicates that stresses in an uncoated graphite frit may not have been sufficient to fracture the material), 3) based on the non-optimal coating process indicated, the failure may not be an inherent design flaw in the fuel element and 4) calculational errors in predicting the thermal expansion of the bed created a situation in which stresses were larger than expected during the higher power transients.

The causes of the remaining three cracks are unresolved but are almost certainly artifacts of the initial failure which we believe to be the first two circumferential breaks. These smaller cracks were probably formed after significant amounts of fuel had relocated into the central gas flow channel. They are not believed to have played an important role in the initial failure of the frit.

The status of the cold frit is puzzling although a calculational error that was made in the pre-test bed expansion model did play a role in the unexpected deformations of the panels. Without more detailed examinations, including accurate deflection measurements of the panels as well as metallographic analysis of the panel material, postulated failures can only be the product of informed speculation.

In our opinion, based on unexpectedly high temperature measurements from the cold frit grid thermocouples and due to the very low power densities and coolant flow rates used during the first phases of the test, there is a significant probability that, along with the error in predictions of the 
total bed expansion, a temperature differential between the compliant panels and the bulk of the cold frit existed during some of the reactor transients. The unexpectedly large values of these gradients produced a bowing force in the panels caused by the thermal expansion mismatch between the panels and the supporting grid structures. Based on the test data and some rough hand calculations, the gradients which were measured would have produced significant panel expansions (greater than the pre-test predictions of the bed expansions at the maximum temperature expected to be achieved in the entire test matrix).

However, after correcting the prediction model errors, new analyses using the maximum temperatures achieved during NET-1.2-9 showed agreement with the amount of panel deformation that was measured during the PIE indicating that the modeling error was probably the primary contributor to the apparently anomalous panel behavior.

Although the thermal bowing problem of the panels could be reduced or eliminated by implementing the cantilever panel design strategy that has already been considered by B\&W, we feel that additional study and testing is warranted to fully understand the response behavior of whatever mechanism is used to maintain the separation of the fuel particle bed with the inner cold frit wall.

All other components that were inspected showed no visible signs of anomalous behavior. This includes the fuel particles which were examined with the SEM and found not to be thermally threatened by all of the reactor testing that occurred in the NET-1.2 experiment. Slight levels of coating oxidation were observed, as expected, although no evidence of significant reaction could be found. This confirms the data recorded during the experiment that the fuel particles were never thermally challenged.

Although several of the test matrix runs were cancelled due to the hot frit failure (including all of the high power density runs), we feel that the results of the PIE indicate that design changes, coupled with increased analytical sophistication (especially with regards to all thermally participating capsule structures) would be necessary to allow production of a fuel element that would withstand the NET-1.2 test matrix. 


\section{REFERENCES}

1. Paliga, Randall, "NET-1.2 Post Irradiation Exam (PIE) Plan," Babcock \& Wilcox Document No. 51-3002082-000, August, 1993.

2. Talley, Darren, G., "Nuclear Element Test Post Irradiation Examination Experiment Plan," Sandia National Laboratories, internal document, October, 1993.

3. Mitchell, G., "NET-1.2 Experiment Plan (including capsule drawings)," Sandia National Laboratories Document, April 14, 1993.

4. Brandsberg, T.A., "Thermal Stress Evaluation of the NET-1.2 Hot Frit Failure," Babcock \& Wilcox Document No. 12-3002119-00, May 20, 1994.

5. Brandsberg, T.A., "Evaluation of Niobium Carbide Coating on Hot Filter Tensile Properties," Babcock \& Wilcox Document No. 12-3002101-00, May 20, 1994. 


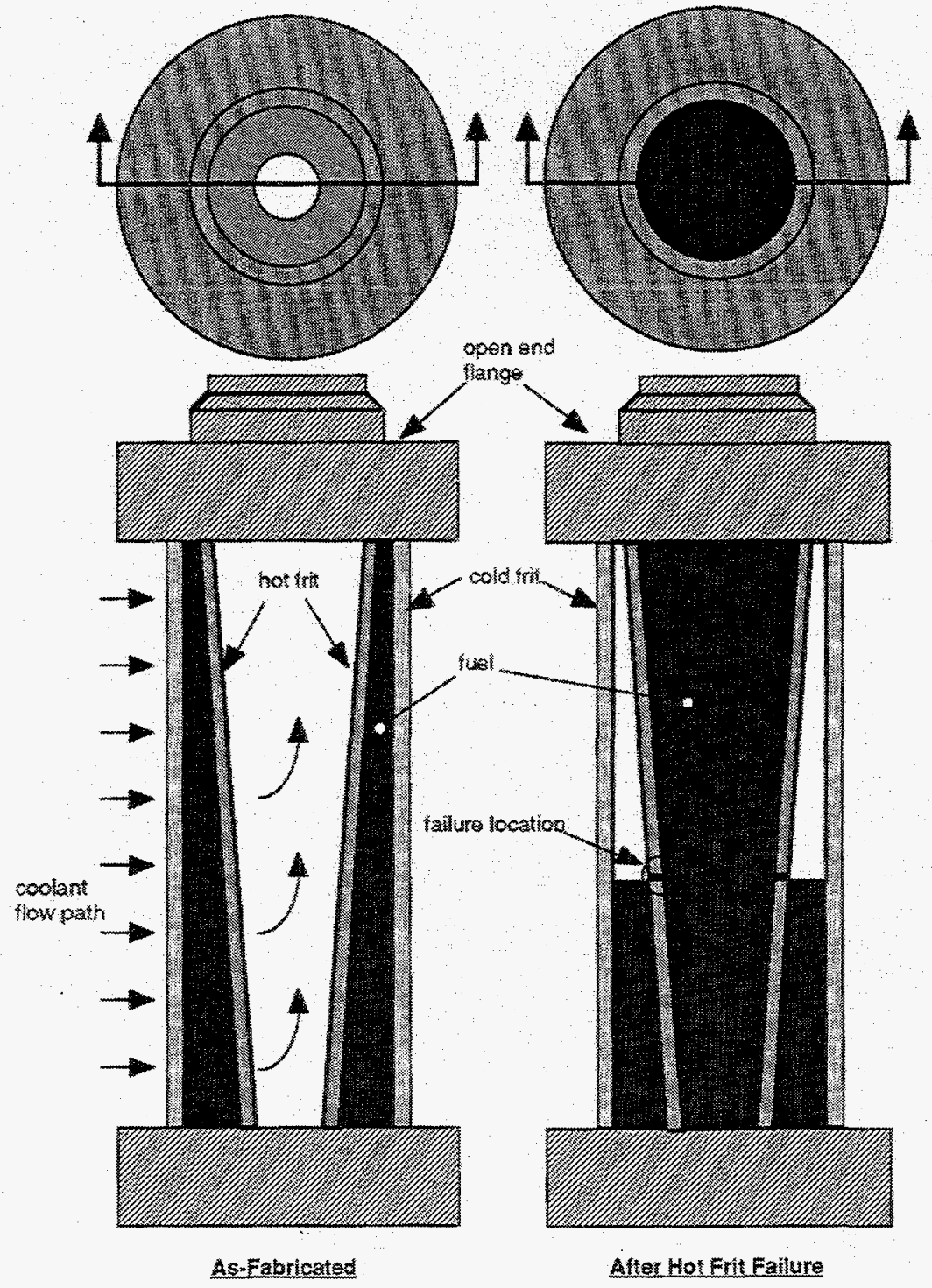

Figure 1. Sketch of the NET Fuel Element 

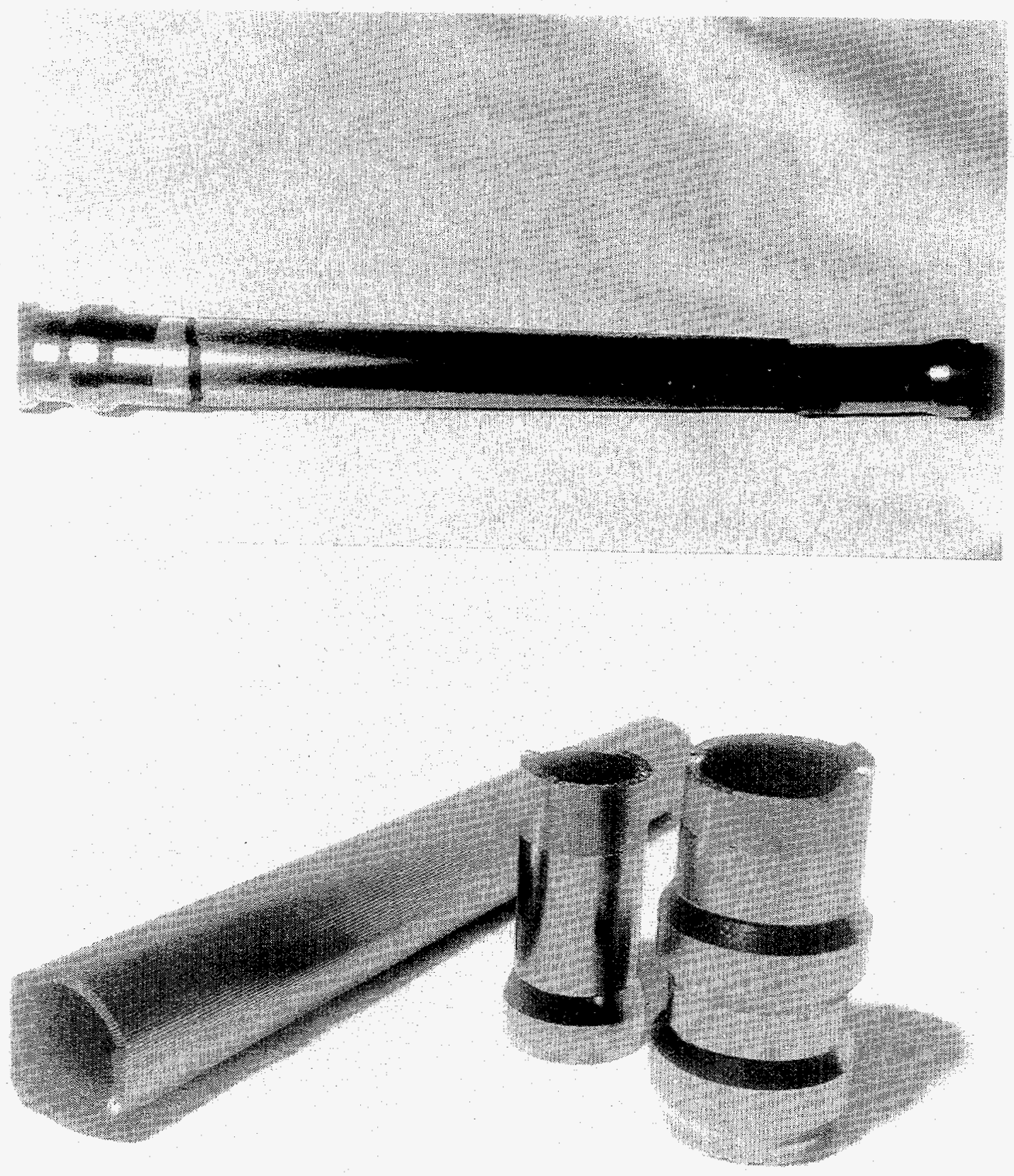

9.6\% $39 \%$

Figure 2. Hot Frit Sections in Relative Positions 

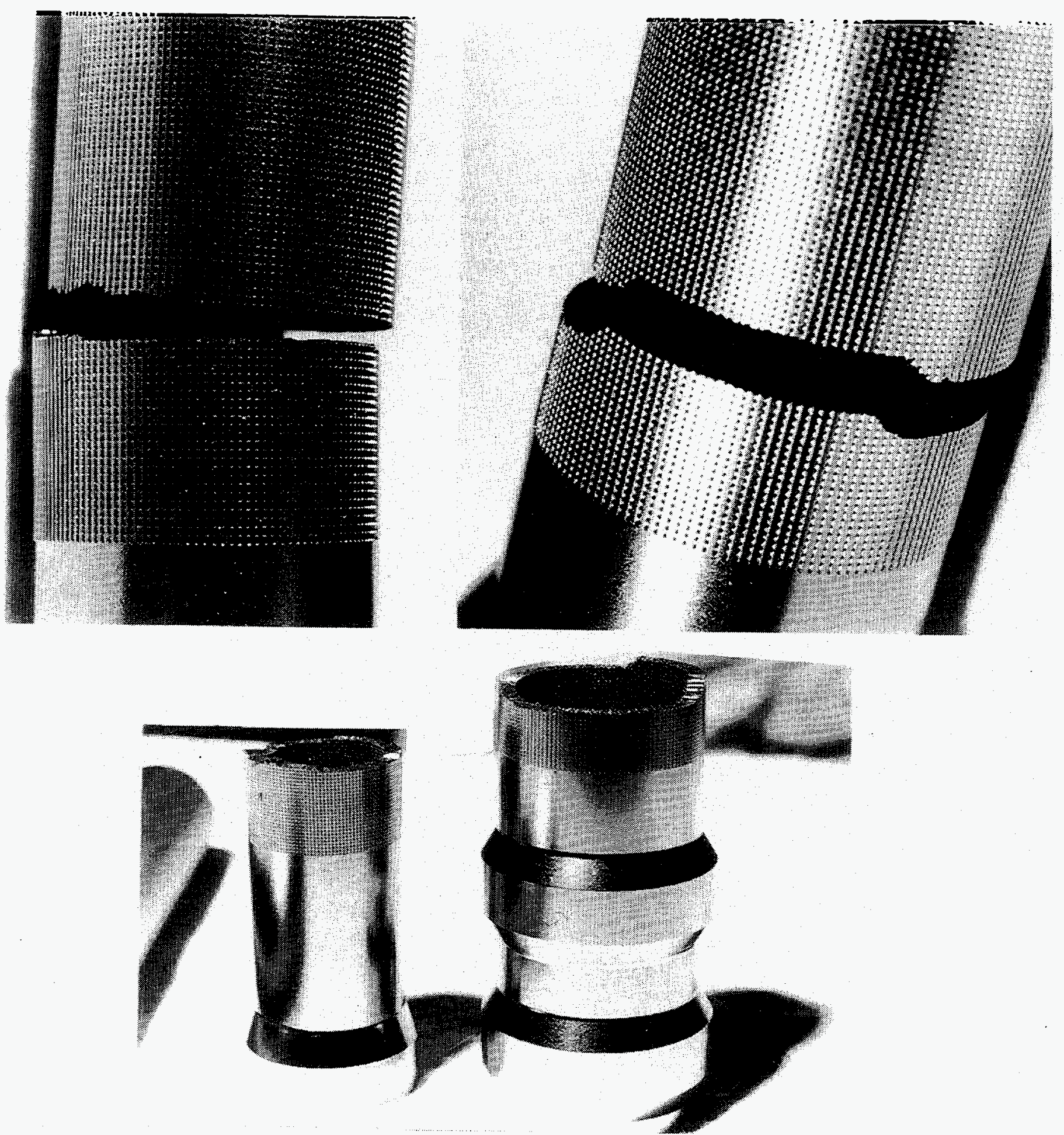

Figure 3. Primary Circumferential Breaks (Open and Closed End Pieces, Upper Two Photos at 2.5 X) 


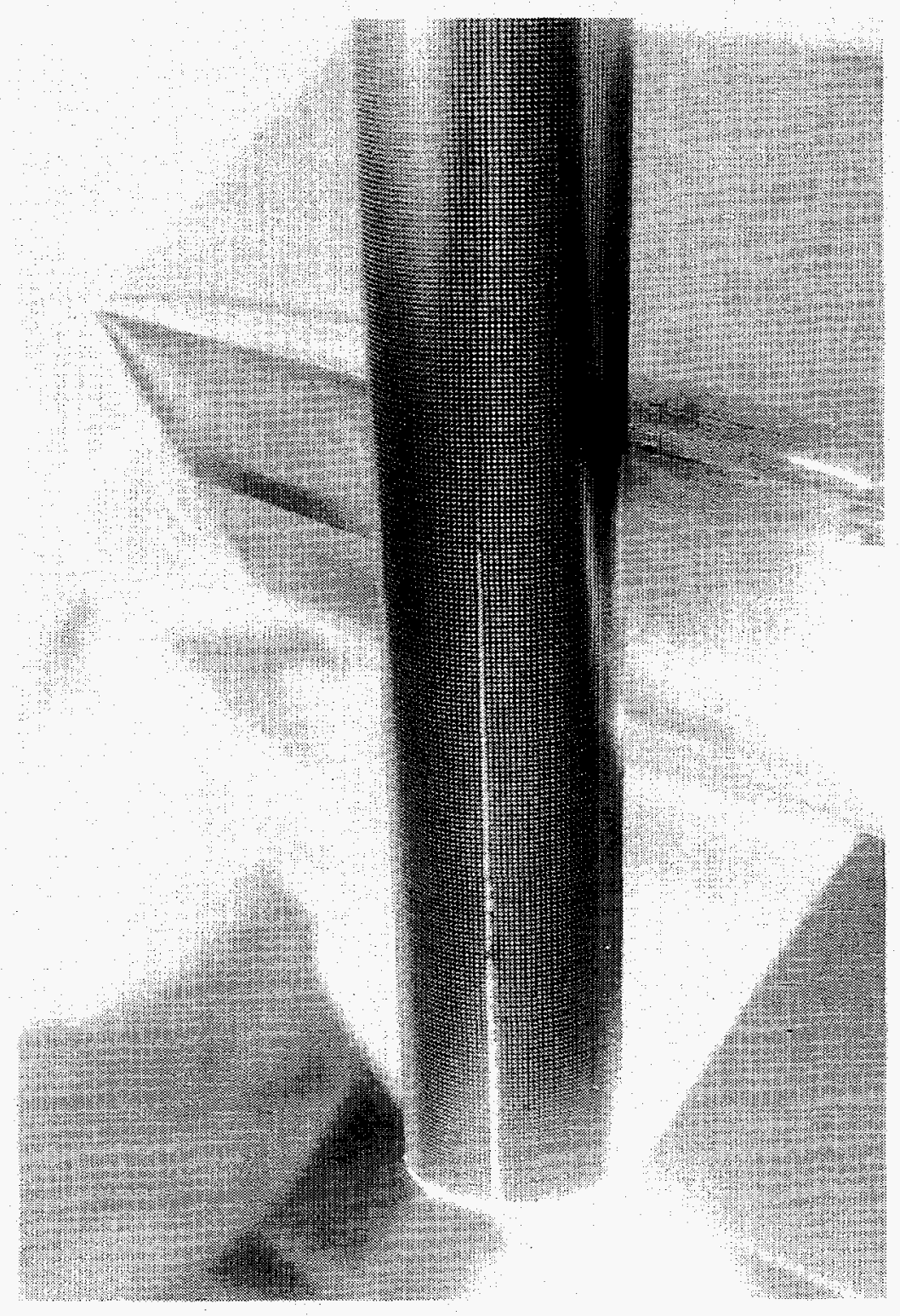

Figure 4. Photomacrograph of Crack \#3 
(a)

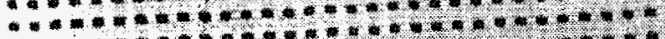
:

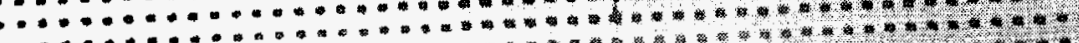
Min a

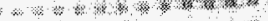

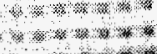

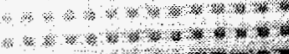
a is

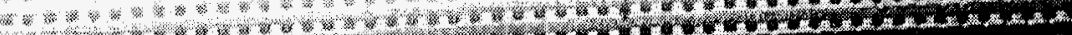

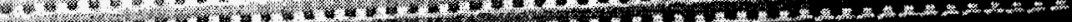
1.0. (1)

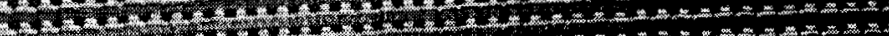

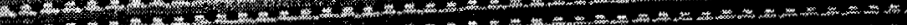

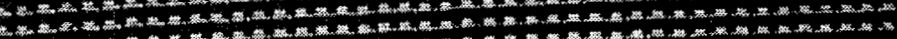

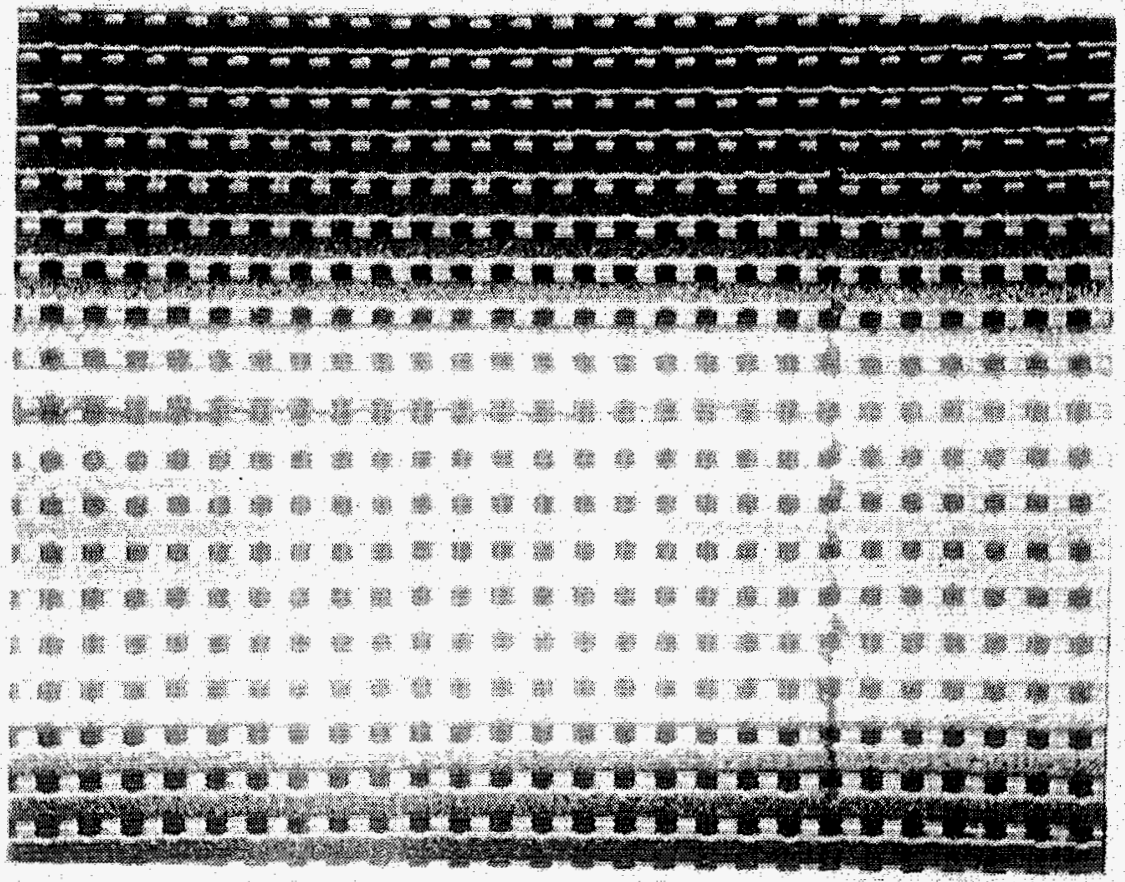




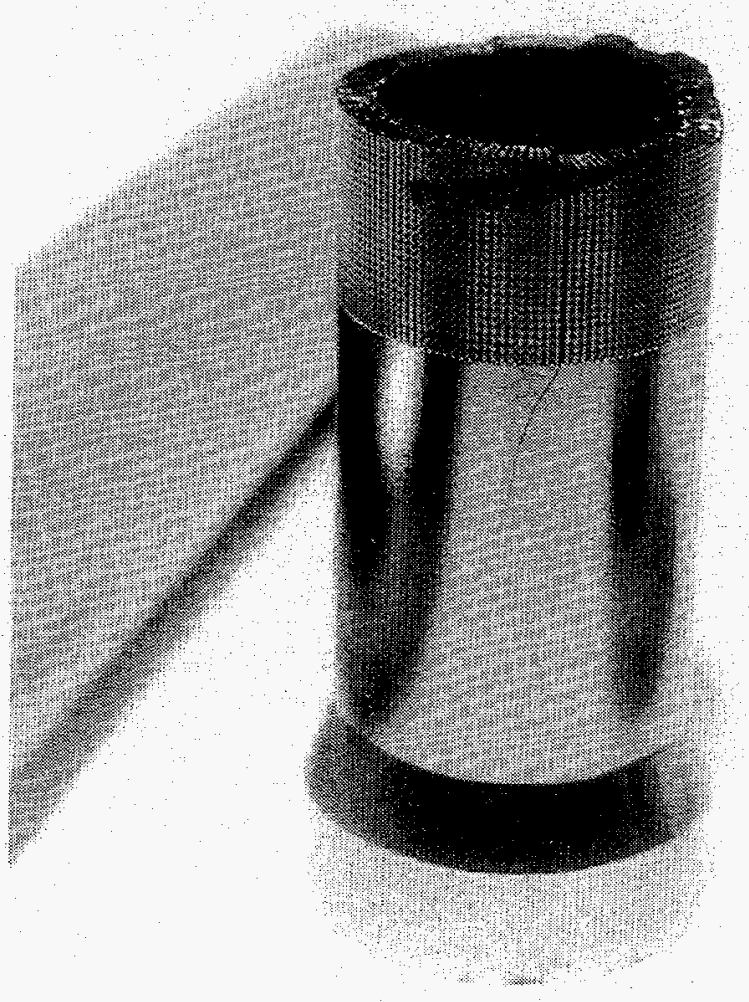

Figure 6. Photomacrograph of Crack \#5 


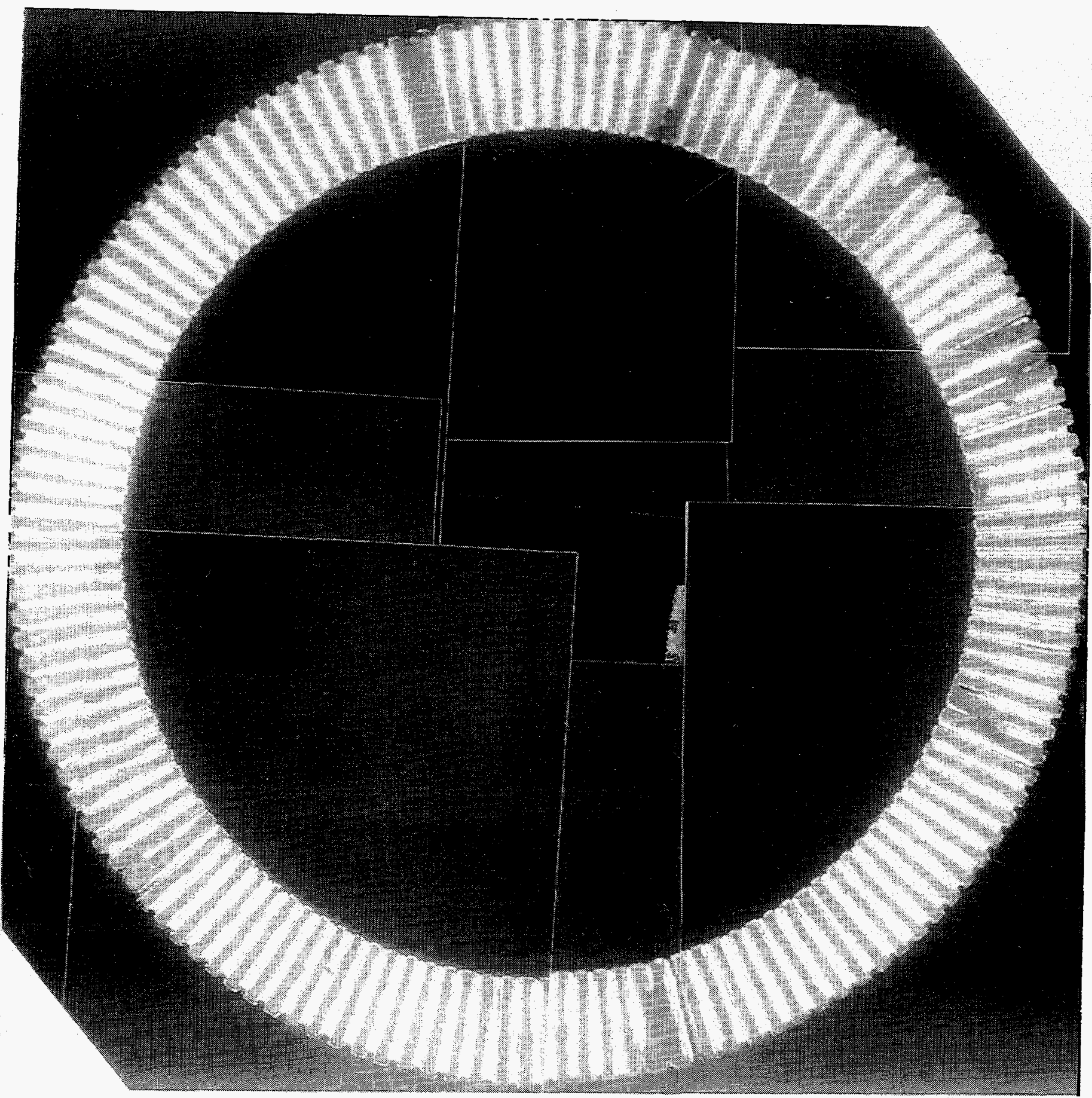

Figure 7. Closed End Fracture Photograph 


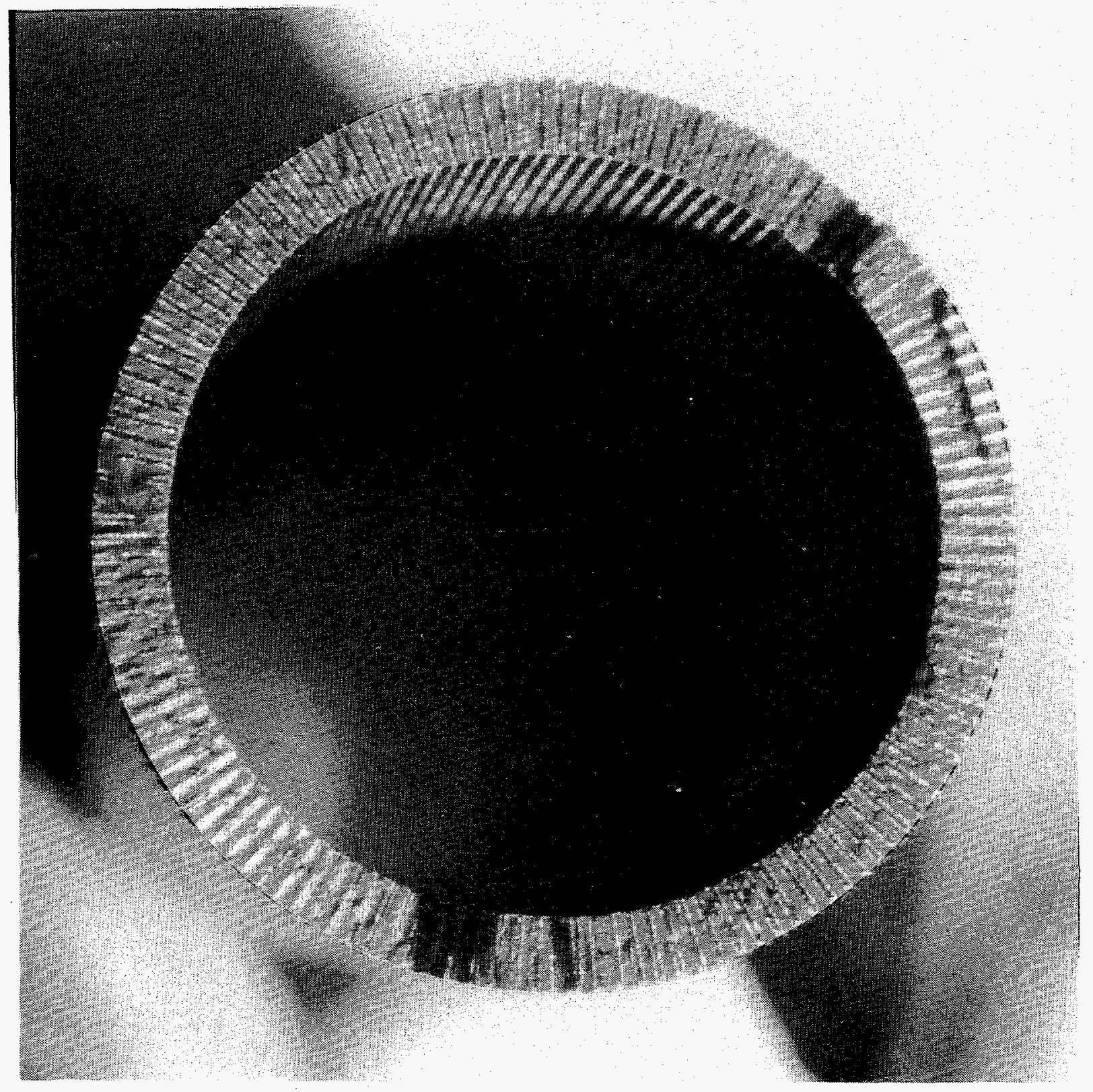

Figure 8. Open End Fracture Photomicrograph (Original Magnification of 20X, Each Print) 


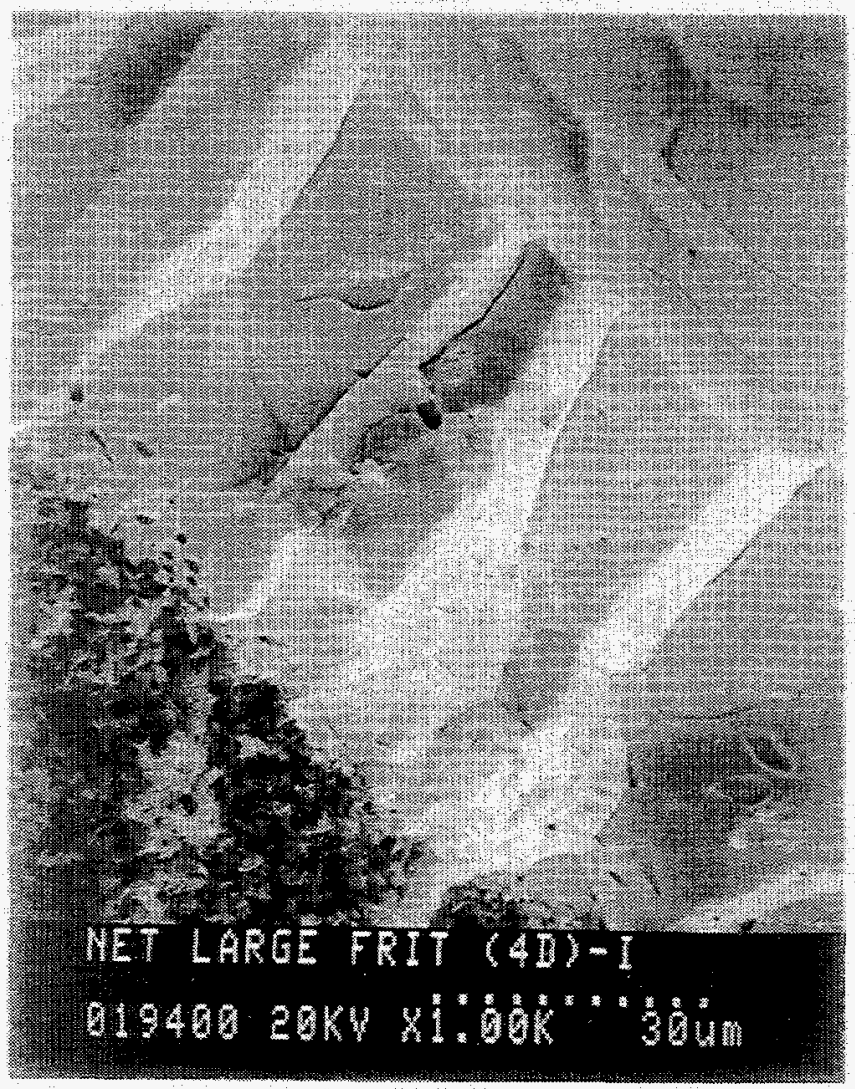

Figure 9a. Fracture Surface SEM Photograph (MagnificationShown) 


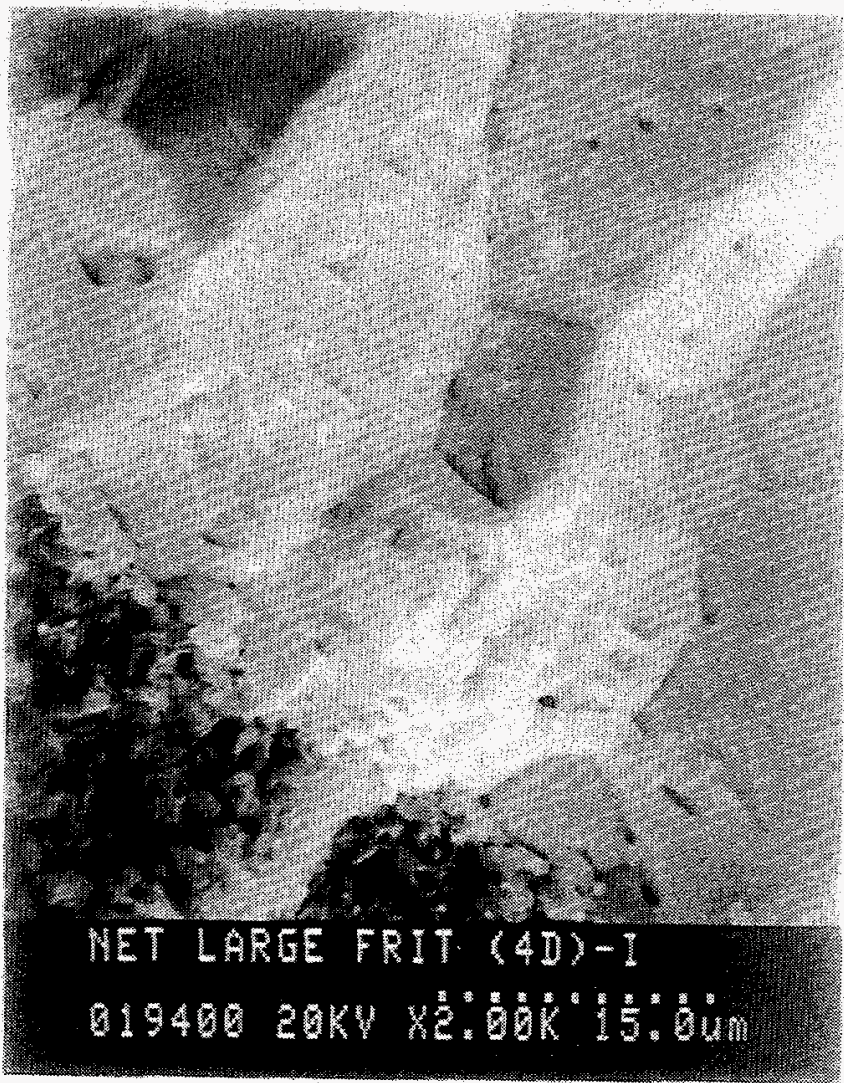

Figure 9b. Fracture Surface SEM Photograph (MagnificationShown) 


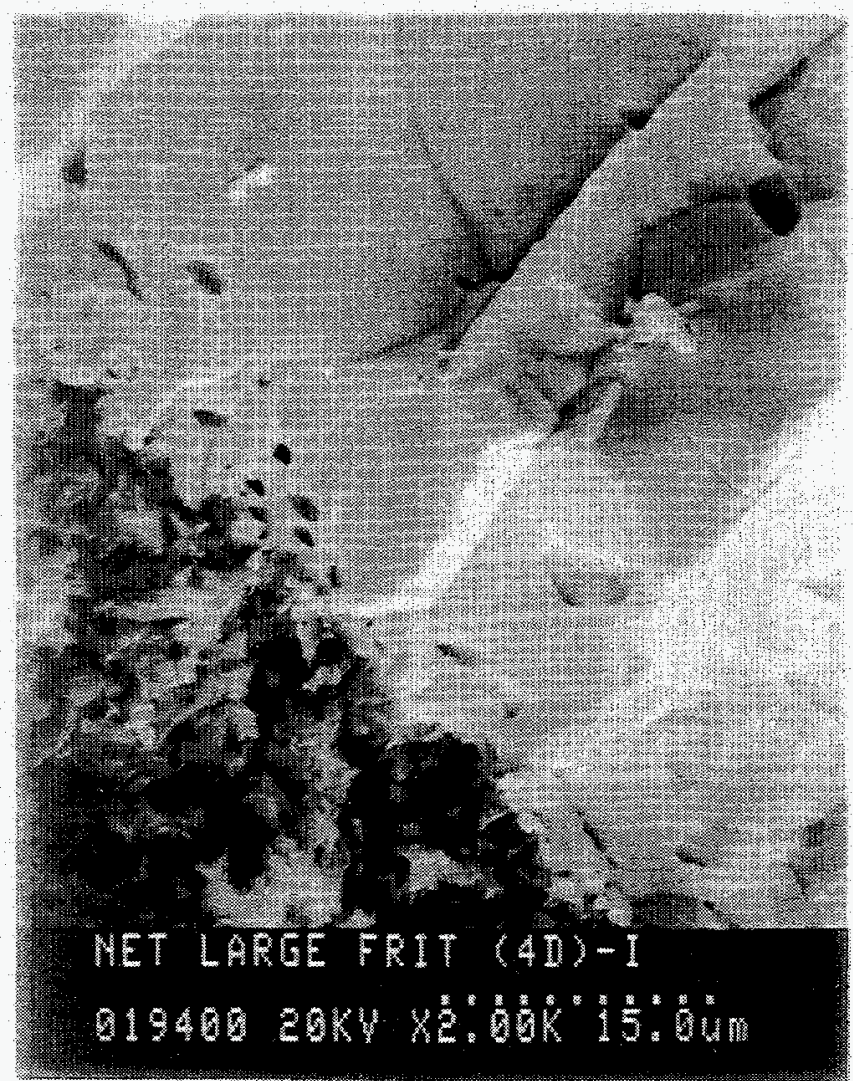

Figure 9c. Fracture Surface SEM Photograph (MagnificationShown) 


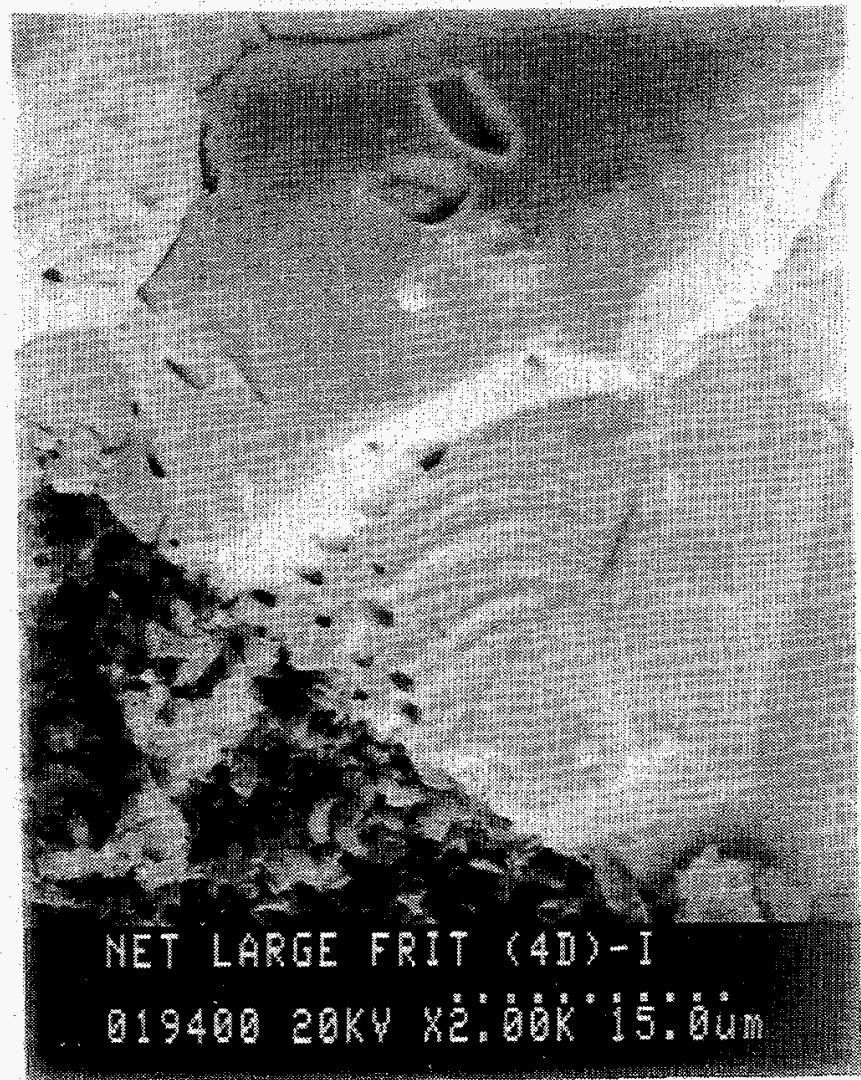

Figure 9d. Fracture Surface SEM Photograph (MagnificationShown) 


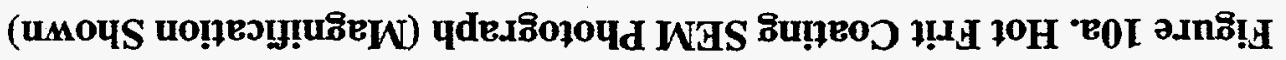

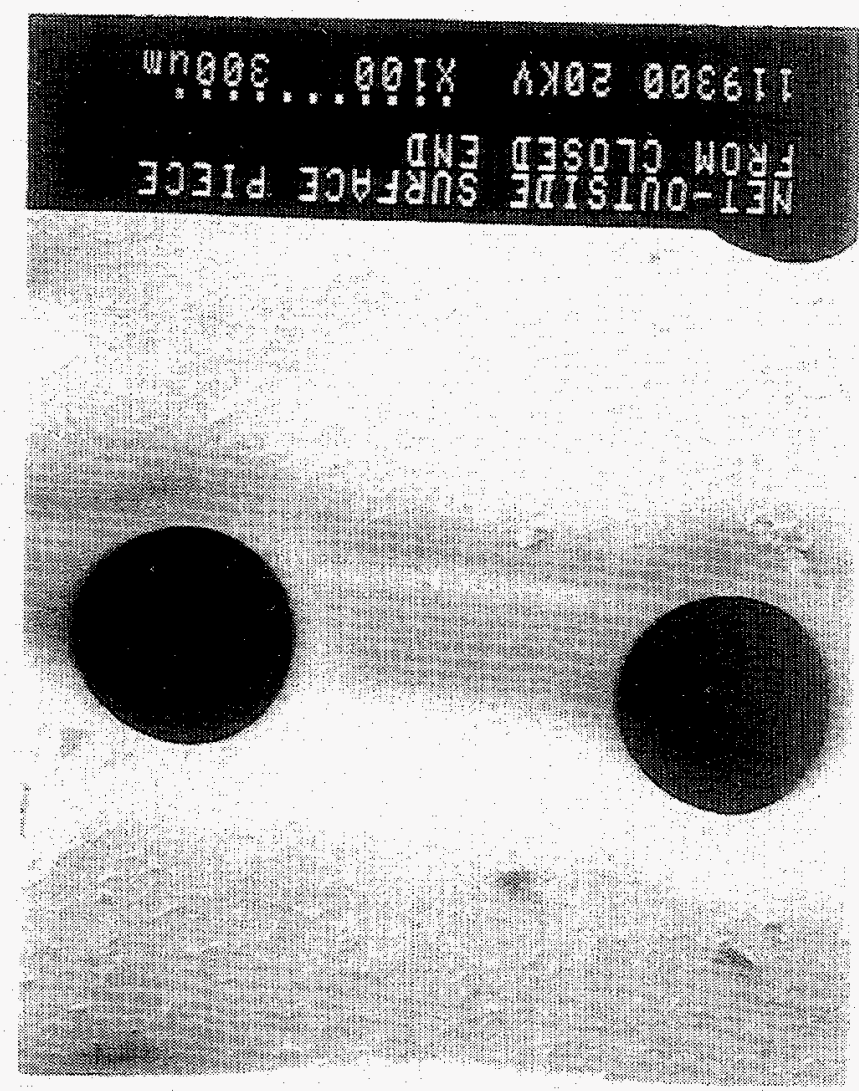




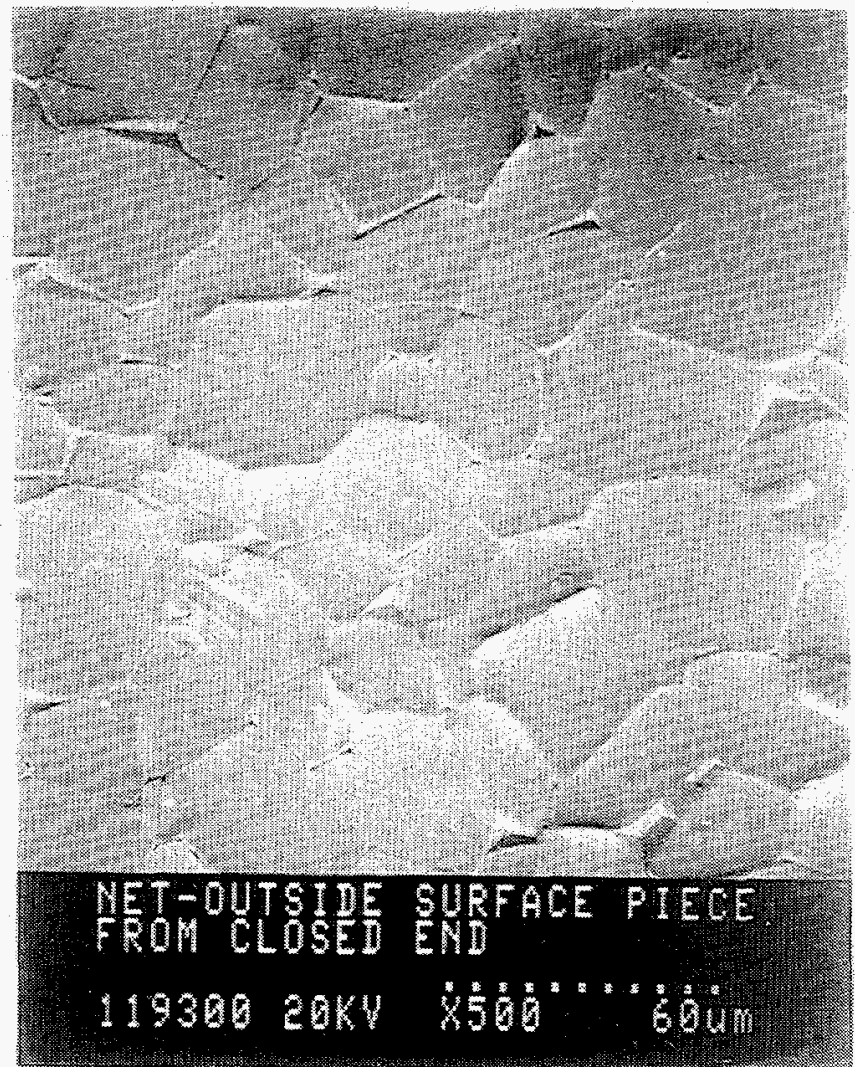

Figure 10b. Hot Frit Coating SEM Photograph (Magnification Shown) 


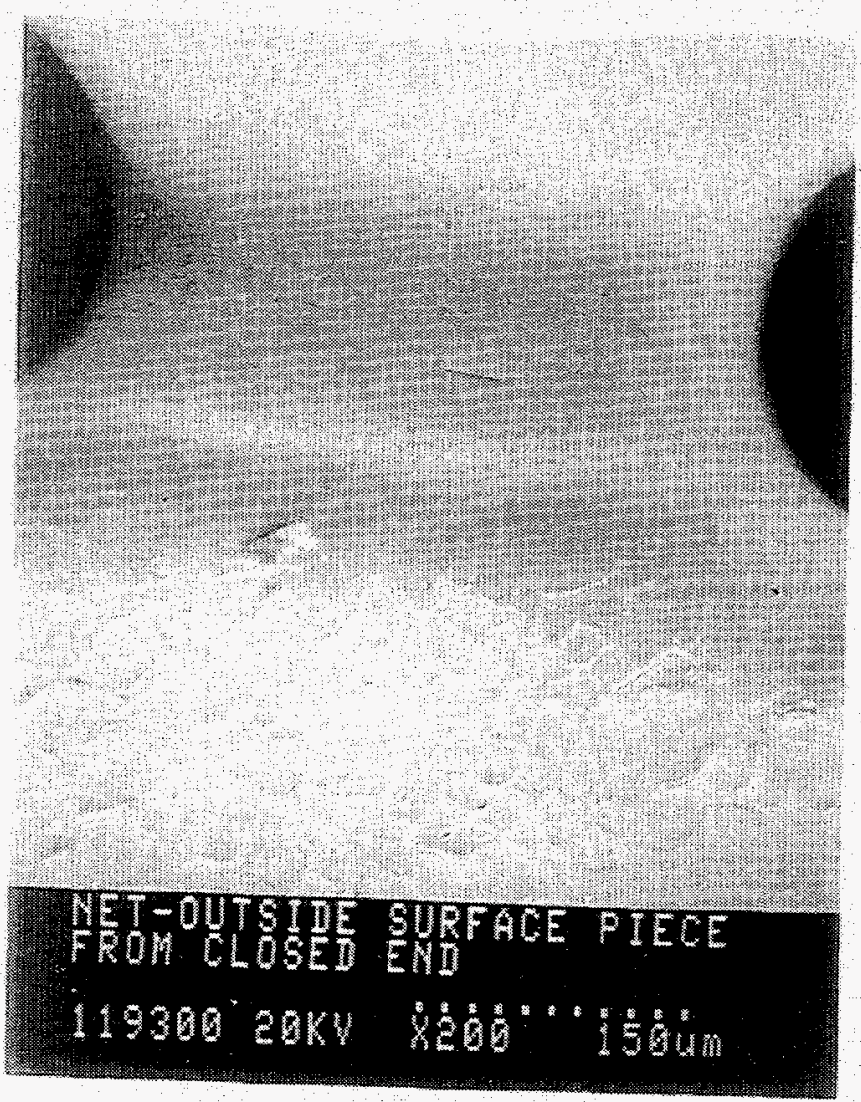

Figure 10c. Hot Frit Coating SEM Photograph (Magnification Shown) 


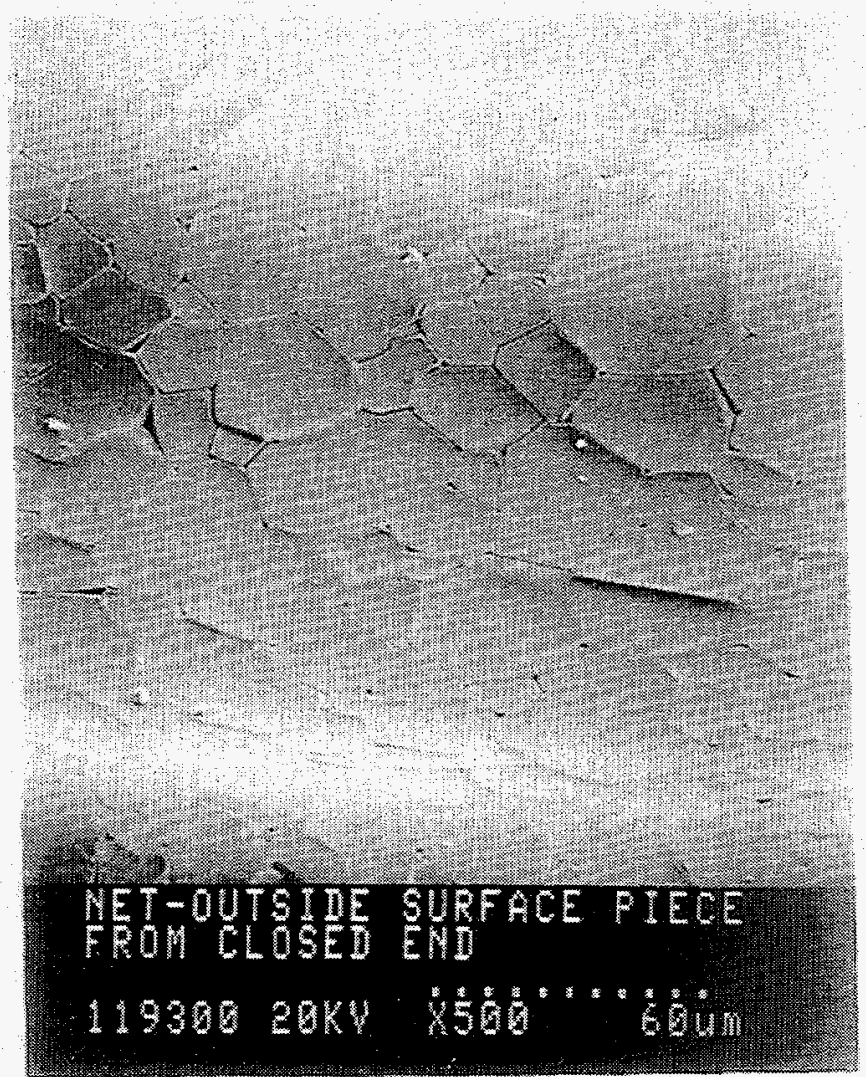

Figure 10d. Hot Frit Coating SEM Photograph (Magnification Shown) 
SAND94-1261

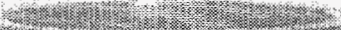

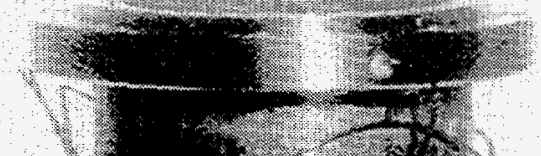

NET-1.2 PIE Report

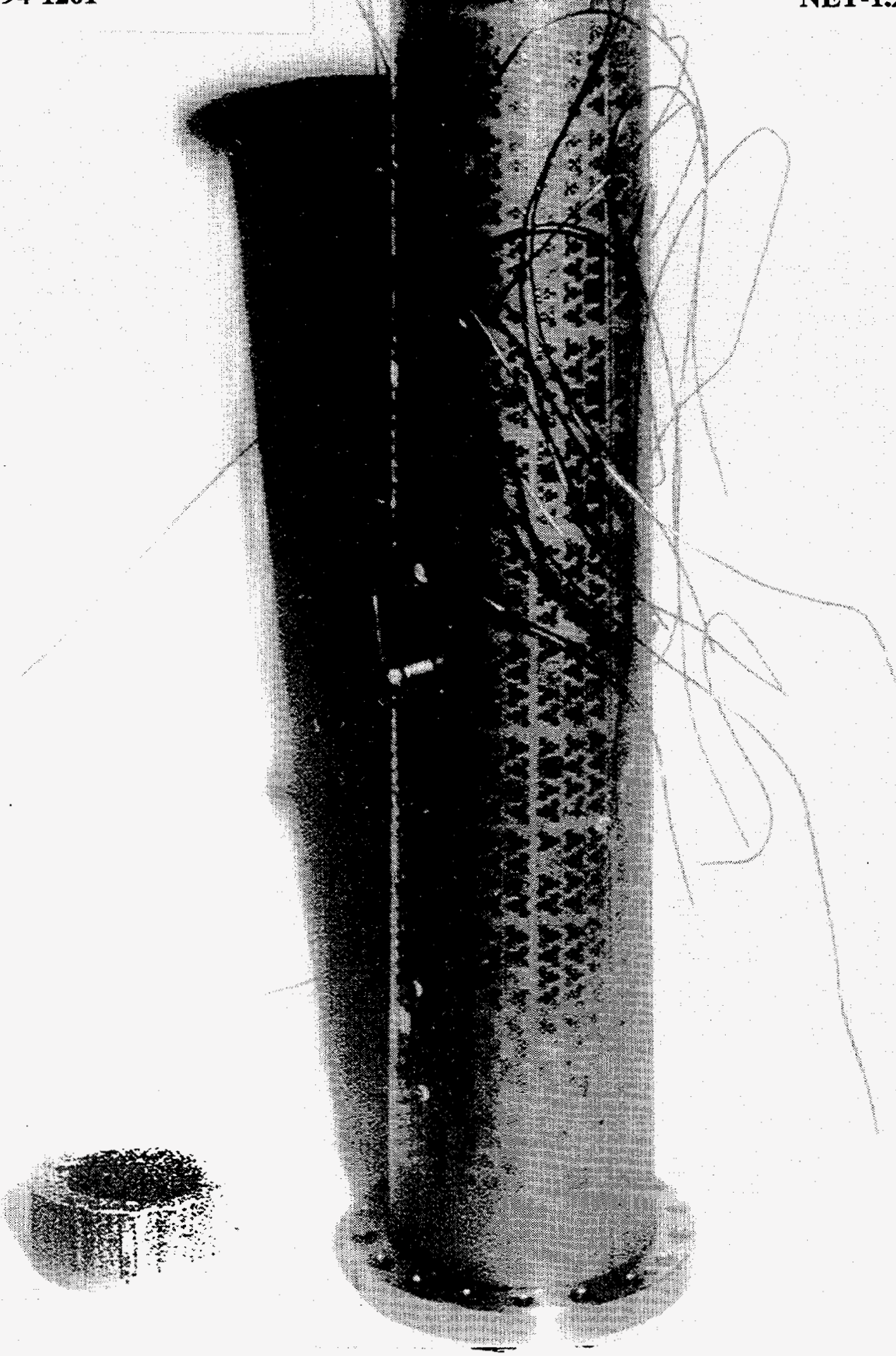

Figure 11. Cold Frit Exterior (with thermocouple lead wires visible) 


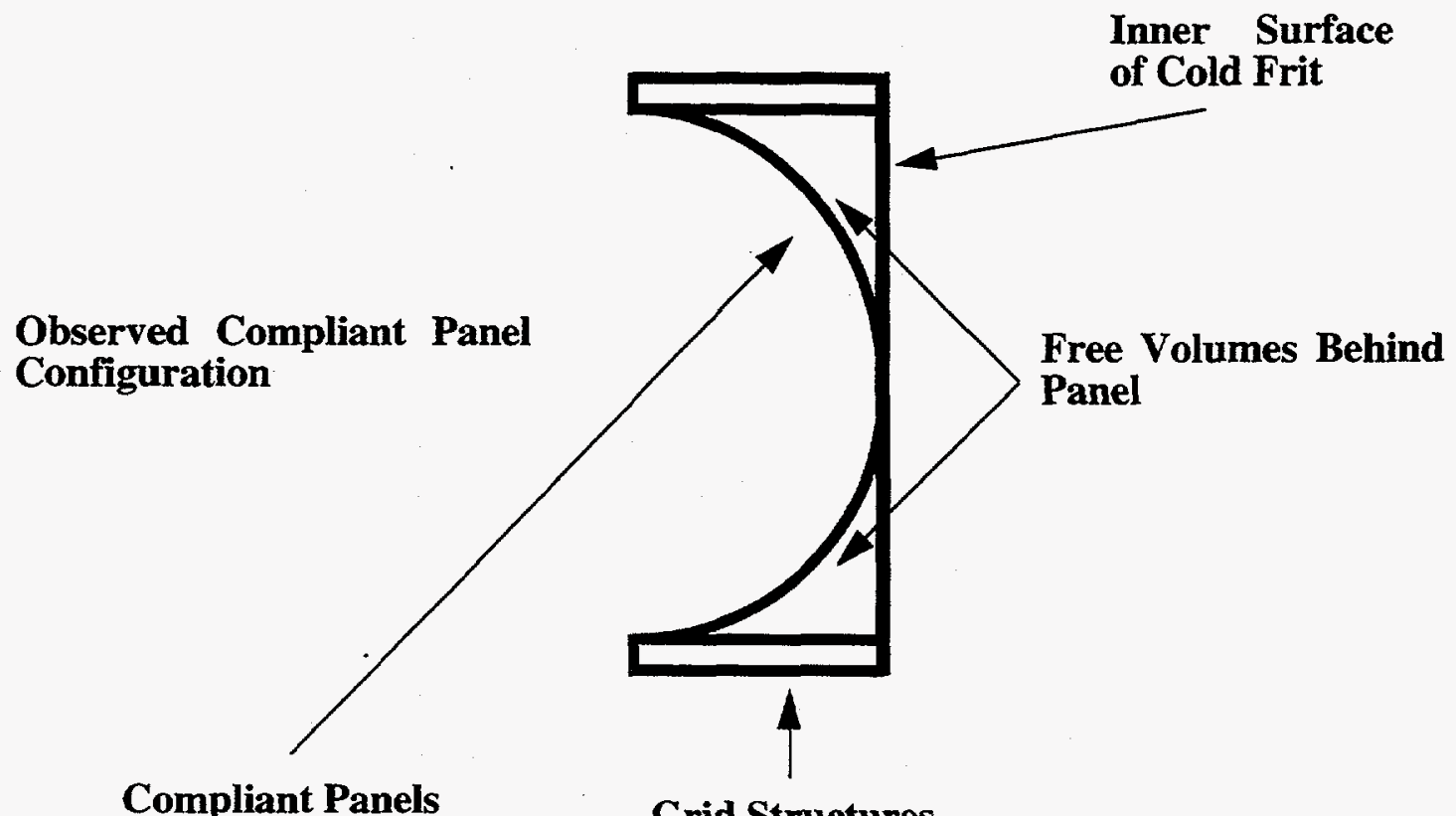

Compliant Panels Grid Structures

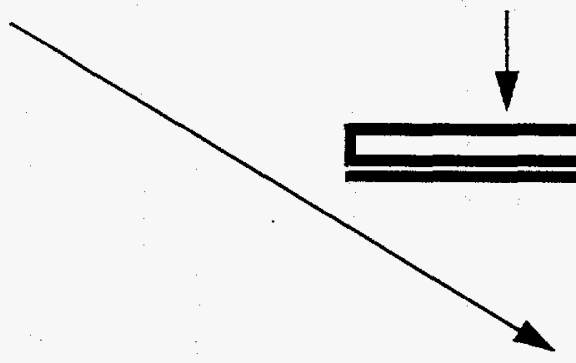

Predicted Bed Locked Compliant

Panel Configuration

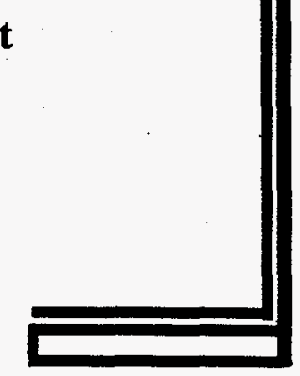

Figure 12. Sketch of Observed Compliant Panel and Predicted Bed Locked Configurations 


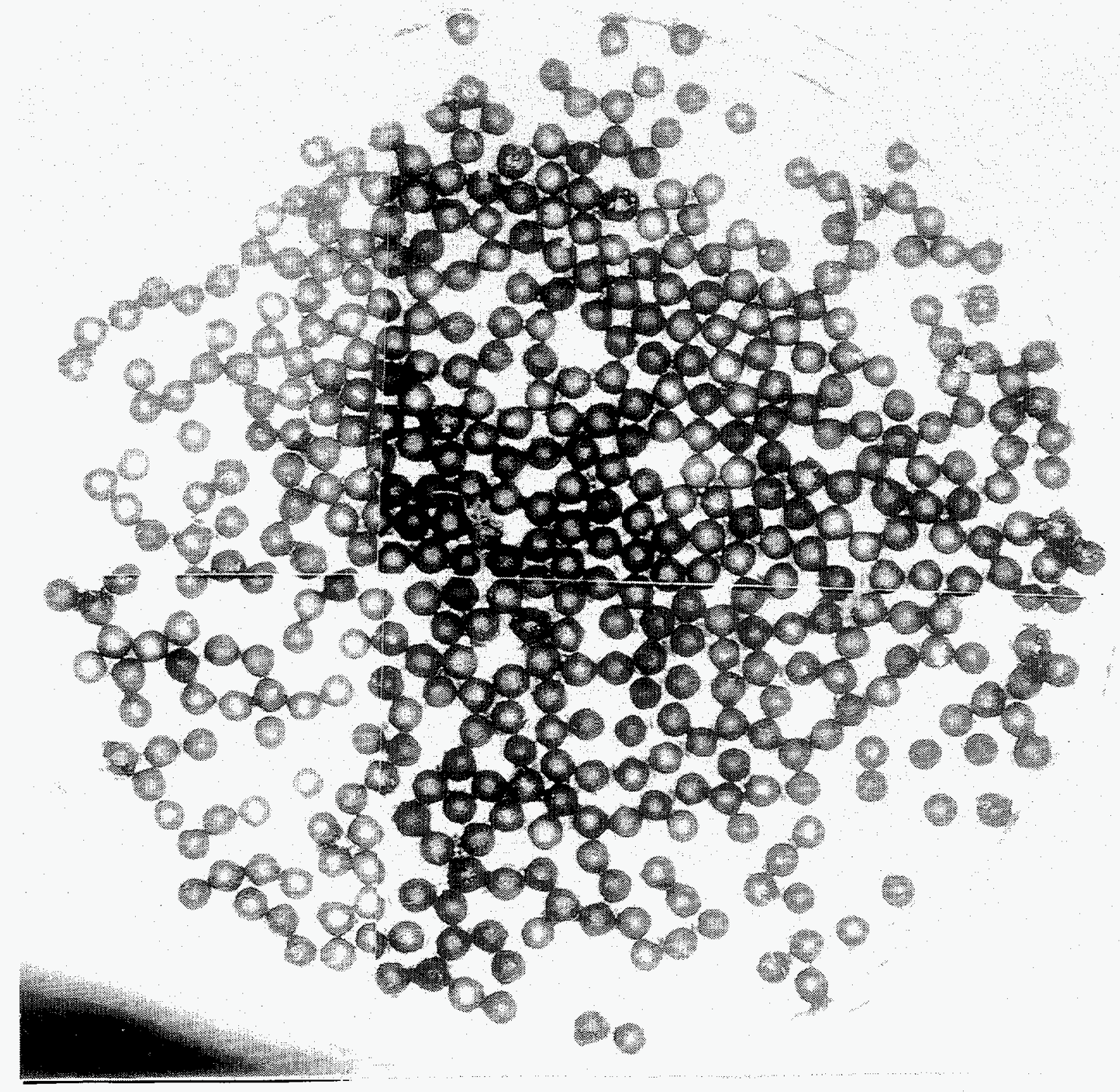

Figure 13. Optical Macrograph of Representative Whole Particle Fuel (the dark color indicates nominal coating oxidation, original magnification $25 \mathrm{X}$ ) 


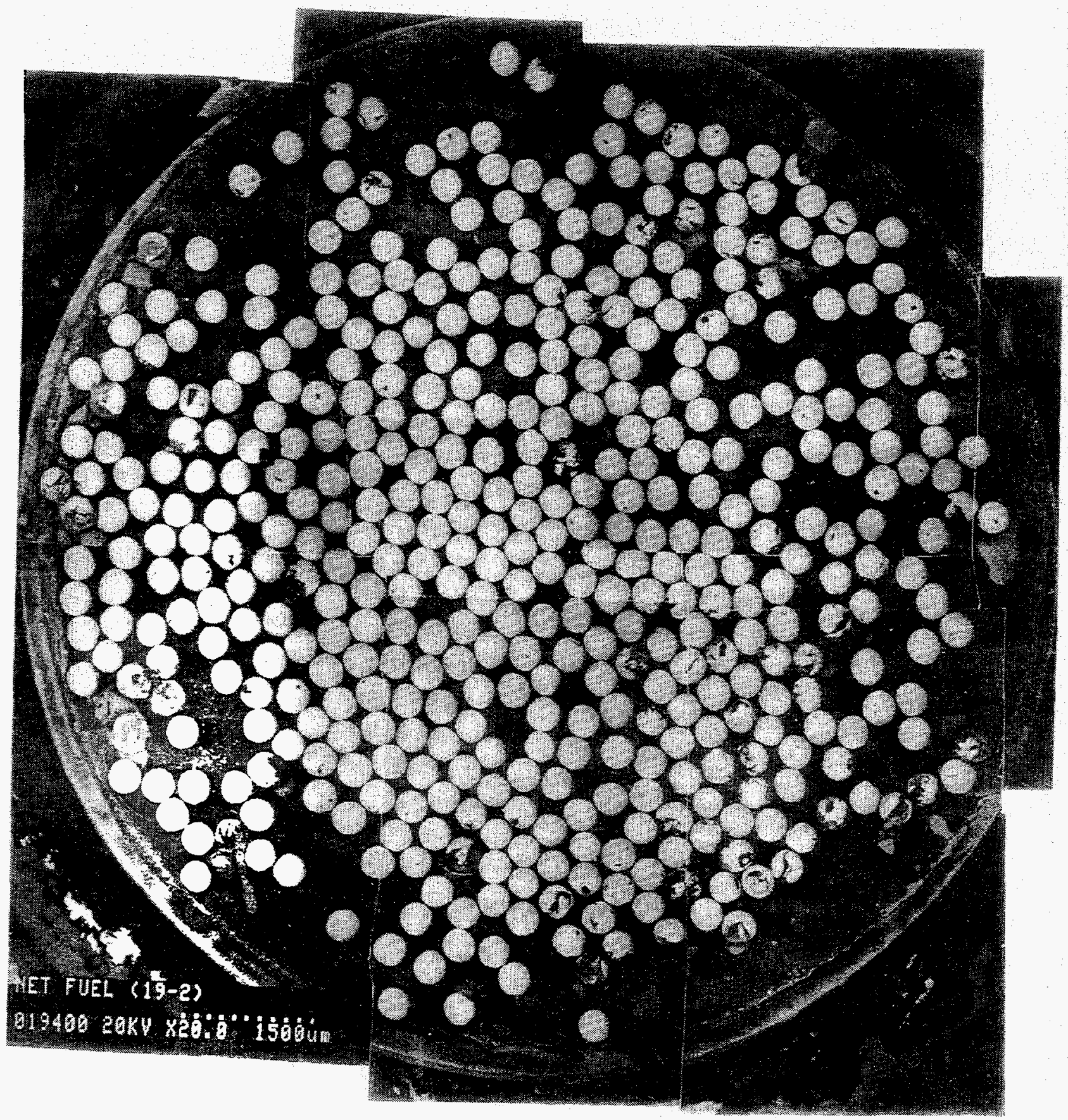

Figure 14. Scanning Electron Micrograph of Representative Whole Particle Fuel (original magnification $25 \mathrm{X}$, as shown) 


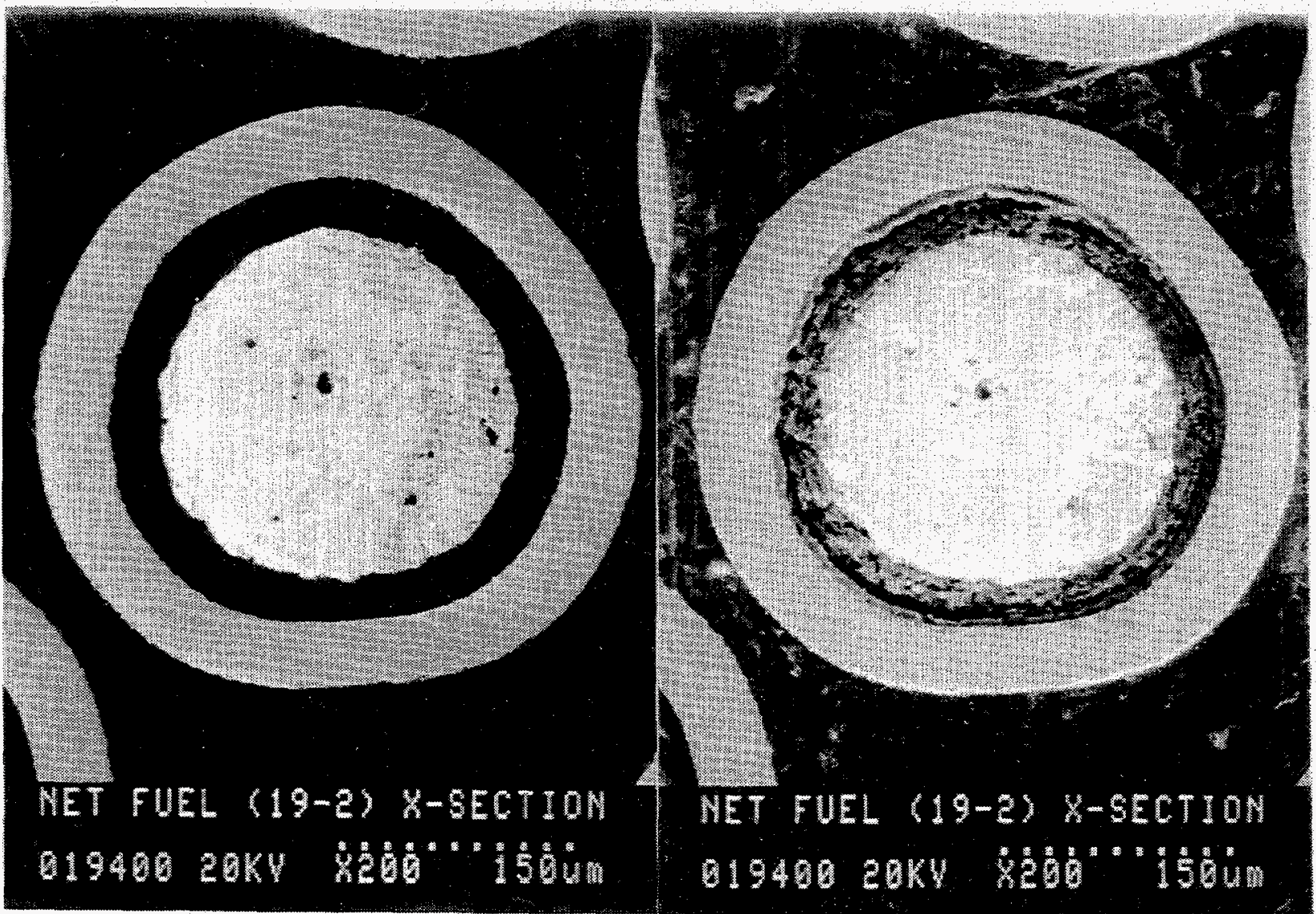

Figure 15. Cross-Sectioned Representative Fuel Particles (Magnification Shown) 


\section{Distribution}

\section{Internal:}

$\begin{array}{llll}\text { MS0756 } & \text { G. C. Allen, Jr. } & 6610 & \\ \text { MS1145 } & \text { S. C. Bourcier } & 9361 & \text { (5 copies) } \\ \text { MS1145 } & \text { J. W. Fisk } & 9363 & \\ \text { MS0744 } & \text { C. D. Harmon } & 6403 & \\ \text { MS1145 } & \text { G. A. Harms } & 9363 & \\ \text { MS1145 } & \text { D. A. McArthur } & 9363 & \\ \text { MS1145 } & \text { G. W. Mitchell } & 9361 & \\ \text { MS1145 } & \text { E. J. Parma } & 9361 & \\ \text { MS1145 } & \text { P. S. Pickard } & 9360 & \\ \text { MS1175 } & \text { N. K. Ries } & 9364 & \text { (5 copies) } \\ \text { MS1175 } & \text { G. S. Rightley } & 9364 & \\ \text { MS1081 } & \text { M. J. Rightley } & 1276 & \text { (5 copies) } \\ \text { MS1145 } & \text { A. J. Suo-Antilla } & 9363 & \\ \text { MS1145 } & \text { D. G. Talley } & 9361 & \\ \text { MS1175 } & \text { M. F. Young } & 9364 & \\ \text { MS1145 } & \text { S. A. Wright } & 9363 & \\ \text { MS0899 } & \text { Technical Library } & 4916 & \text { (5 copies) } \\ \text { MS9019 } & \text { Central Technical Files } & 8940 & \text { (2 copies) } \\ \text { MS0619 } & \text { Review \& Approval Desk } & 12690 & \text { (2 copies) }\end{array}$

\section{External:}

Jerry Gibson

Phillips Laboratory/VT-X

3550 Aberdeen Ave S.E.

Kirtland AFB, NM 87117-5776 